\title{
Aggregation, Heterogeneous Autoregression and Volatility of Daily International Tourist Arrivals and Exchange Rates*
}

\author{
Chia-Lin Chang \\ Department of Applied Economics \\ Department of Finance \\ National Chung Hsing University \\ Taichung, Taiwan \\ Michael McAleer \\ Econometric Institute \\ Erasmus School of Economics \\ Erasmus University Rotterdam \\ and \\ Tinbergen Institute \\ The Netherlands \\ and \\ Institute of Economic Research \\ Kyoto University \\ and \\ Department of Quantitative Economics \\ Complutense University of Madrid
}

Revised: May 2011

\footnotetext{
${ }^{1}$ Corresponding author: Chia-Lin Chang, Department of Applied Economics National Chung Hsing University Taichung, 250 Kuo Kuang Road, National Chung Hsing University Taichung 402, Taiwan, changchialin@nchu.edu.tw, Tel: +886 (04)22840350 ext 309. Fax: +886(04)22860255.

* The authors are most grateful for the helpful comments and suggestions of the Editor and a referee. For financial support, the first author wishes to thank the National Science Council, Taiwan, and the second author acknowledges the Australian Research Council, National Science Council, Taiwan, and the Japan Society for the Promotion of Science.
} 


\begin{abstract}
Tourism is a major source of service receipts for many countries, including Taiwan. The two leading tourism countries for Taiwan are Japan and USA, which are sources of short and long haul tourism, respectively. As a strong domestic currency can have adverse effects on international tourist arrivals through the price effect, daily data from 1 January 1990 to 31 December 2008 are used to model the world price, exchange rates, and tourist arrivals from the world, USA and Japan to Taiwan, and their associated volatility. Inclusion of the exchange rate and its volatility captures approximate daily and weekly price and price volatility effects on world, US and Japanese tourist arrivals to Taiwan. The Heterogeneous Autoregressive (HAR) model is used to approximate the slowly decaying correlations associated with the long memory properties in daily and weekly exchange rates and international tourist arrivals, to test whether alternative short and long run estimates of conditional volatility are sensitive to the long memory in the conditional mean, to examine asymmetry and leverage in volatility, and to examine the effects of temporal and spatial aggregation. The approximate price and price volatility effects tend to be different, with the exchange rate typically having the expected negative impact on tourist arrivals to Taiwan, whereas exchange rate volatility can have positive or negative effects on tourist arrivals to Taiwan. For policy purposes, the empirical results suggest that an arbitrary choice of data frequency or spatial aggregation will not lead to robust findings as they are generally not independent of the level of aggregation used.
\end{abstract}

Keywords: International tourist arrivals, exchange rates, exchange rate volatility, GARCH, GJR, EGARCH, HAR, long memory, temporal and spatial aggregation, daily and weekly effects, asymmetry, leverage.

JEL Classifications: C22, F31, G18, G32. 


\section{Introduction}

Tourism is a major source of service receipts for many countries, including Taiwan. The two leading tourism countries for Taiwan, comprising a high proportion of world tourist arrivals to Taiwan, are Japan and USA, which are sources of short and long haul tourism, respectively. Although more than three million international tourists visited Taiwan in 2008, the major part of the Taiwan tourist industry is supported by domestic tourism. Taiwan's extensive network of trains and highways makes it possible to traverse the country (north-south) in less than two hours by the new high speed train, and in a few hours by car. The most well known tourist attractions in Taiwan include the spectacular National Palace Museum (Taipei), home to some of Chinese greatest antiquities, the amazing Night Markets throughout the country, Taipei 101, formerly the world's tallest building, relaxing Sun Moon Lake (near Puli in the central highlands), and stunning Taroko National Park in Hualian on the east coast.

A major purpose in tourism marketing is to increase total tourism expenditure receipts. If the daily expenditure per international tourist were to be reasonably constant over the sample period, then international tourist arrivals and total international tourism expenditure would be highly correlated. Moreover, the rate of growth in daily international tourism expenditure and the rate of growth in daily international tourist arrivals would then be virtually identical.

As it is well known that a strong domestic currency can have adverse effects on international tourist arrivals through the price effect and its associated volatility, one of the primary purposes of the paper is to model daily tourist arrivals to Taiwan from the world, USA and Japan, and the world price and US\$ / New Taiwan \$ and Yen/ New Taiwan \$ exchange rates, and their respective volatilities. Daily data from 1 January 1990 to 31 December 2008 are obtained from the National Immigration Agency of Taiwan for daily world, US and Japanese tourist arrivals, the Bloomberg database for the two foreign exchange rates, and the Reuters database for the world price.

In order to manage international tourist arrivals from the major tourism sources, as well as tourism growth and its corresponding volatility, it is necessary to model adequately international tourist arrivals and their associated volatility, especially in the presence of significant economic and financial shocks. In light of the 2008-09 global financial crisis, its significant economic impact on the tourism industry in Taiwan and internationally, and the need for a speedy and informative analysis of the level of international tourist arrivals, their growth rates and associated volatility, it is 
essential to use daily data rather than the usual monthly, quarterly or annual data that have traditionally been used in previous empirical tourism studies.

Daily data permit an appeal to the theoretical results available in financial econometrics, and an approximation of the modelling and forecasting strategies widely used in financial time series analysis. From a time series perspective, there are several reasons for using daily data rather than lower frequencies such as monthly, quarterly or annual data (see, for example, McAleer (2009)). In addition to the use of much larger sample sizes than those associated with monthly, quarterly or annual data, the use of daily data permits an examination of whether the time series properties have changed. The time series behaviour at other temporal frequencies, such as weekly data, can be obtained by aggregation of daily data, so that temporal aggregation effects can be analysed. Moreover, approximate daily price elasticities of the demand for international tourism can be estimated through the use of daily exchange rates, and the daily volatility of international tourism demand and exchange rates can be analysed. The use of daily data enables more immediate responses to be activated in light of generating daily estimates and forecasts of approximate price effects through the exchange rate, and accurate daily forecasts of tourist arrivals and their growth rates, in response to significant economic and financial shocks. In addition, the estimation and forecasting of time-varying conditional volatilities will enable more accurate confidence intervals for international tourist arrivals and their growth rates to be determined on a daily, and if aggregated temporally, on a weekly basis.

The remainder of the paper is organized as follows. Section 2 presents the daily world, US and Japanese tourist arrivals, world price and exchange rate time series data. Section 3 performs unit root tests on the three tourist arrivals series for daily and weekly data. Section 4 discusses approximate long memory conditional mean and conditional volatility models for daily world, US and Japanese tourist arrivals, world price and two exchange rates. The estimated models and empirical results for the heterogeneous autoregressive (HAR) and three univariate conditional volatility models are discussed in Section 5, as are the effects of temporal aggregation from daily to weekly data. Finally, some concluding remarks are given in Section 6.

\section{Data}

The data set comprises daily tourist arrivals from the world, USA and Japan for the period 1 January 1990 to 31 December 2008, giving 6,940 observations obtained from the National 
Immigration Agency of Taiwan, and an equivalent number of observations for the US\$ / New Taiwan $\$$ and Yen/ New Taiwan \$ exchange rates, that are obtained from the Bloomberg database: Taipei Foreign Exchange Market Development Foundation (URL: http://www.tpefx.com.tw). The world price is obtained from Reuters as the Intercontinental Exchange calculation of the US Dollar Index, which is the US \$ relative to a geometric weighted mean of six currencies (namely, Euro, Canadian \$, Japanese yen, Swedish krona, Pound sterling and Swiss franc). Thus, if the US \$ increases relative to the world price, then prices in the USA will be lower, thereby leading to reduced US tourists to Taiwan. Moreover, the higher world price will have a positive income effect for the rest of the world, which will tend to increase world tourist arrivals to Taiwan. Overall, the world price effect on world tourist arrivals to Taiwan would be expected to be negative.

Figures 1-4 plot the daily and weekly tourist arrivals from the world, USA and Japan, and the world price and US\$ / New Taiwan \$ and Yen/ New Taiwan \$ exchange rates, as well as their respective volatilities, where volatility is defined as the squared deviation from the sample mean. There is higher volatility persistence at the end of the sample period, due primarily to the global financial crisis (for further details on the global financial crisis see, for example, McAleer (2009) and McAleer et al. (2009, 2009a, 2009b, 2010)).

Daily and weekly tourist arrivals to Taiwan from the world, USA and Japan, and the corresponding daily and weekly exchange rates, have varied considerably over the sample period, which suggests that the daily and weekly effects of the approximate price movements on international tourism demand might be captured using appropriate heterogeneous time series and conditional volatility models. The exchange rate effects aside, there would seem to be considerable scope for a significant increase in tourism to Taiwan from the world, USA and Japan.

\section{Unit Root Tests}

Standard unit root tests based on the classic methods of Dickey and Fuller $(1979,1981)$ and Phillips and Perron (1988) are available in the econometric software package EViews 6.0, and are reported in Table 1. There is no evidence of a unit root in daily or weekly world, US and Japanese tourist arrivals to Taiwan in the model with a constant and trend as the deterministic terms, or with just a constant, so that daily and weekly series to be modeled are stationary. 
These empirical results allow the use of world, US and Japanese tourist arrivals data to Taiwan, and the three exchange rates, to estimate alternative univariate approximate long memory conditional mean and conditional volatility models given in the next section. Before doing so, it is useful to examine which daily exchange rates should be used for their weekly counterparts. Although not reported here, we calculated the correlation coefficients for the world price and Japanese and US exchange rates for the arithmetic and geometric means of the seven daily prices and exchange rates, as well as for the seven days of the week, for purposes of selecting the appropriate world weekly price and weekly exchange rates for Japan and USA. The correlation coefficients are very close to one in all cases, and the arithmetic and geometric means are identical to three decimal places. For this reason, the arithmetic means of the seven daily world prices and exchange rates are chosen as the respective weekly prices and weekly exchange rates for the world, Japan and USA.

\section{Conditional Mean and Conditional Volatility Models}

There are several model specifications of univariate conditional volatility, with and without asymmetry and/or leverage. The alternative time series models to be estimated for the conditional means of daily and weekly world, US and Japanese tourist arrivals to Taiwan, as well as their respective conditional volatilities, are discussed below. As shown in Figures 1-4, both daily and weekly world, US and Japanese tourist arrivals to Taiwan and the three exchange rates show periods of high volatility, followed by others of relatively low volatility. One implication of this persistent volatility behaviour is that the assumption of (conditionally) homoskedastic residuals is inappropriate.

As discussed in, for example, Divino and McAleer (2009, 2010) and Chang and McAleer (2009), for a wide range of data series in finance, international finance, energy finance and tourism research, time-varying conditional variances can be explained empirically through the autoregressive conditional heteroskedasticity (ARCH) model (Engle (1982)). When the timevarying conditional variance has both autoregressive and moving average components, this leads to the generalized $\operatorname{ARCH}(p, q)$, or $\operatorname{GARCH}(p, q)$ (Bollerslev (1986)), with the lag structure of the appropriate GARCH model typically given as the widely estimated $\operatorname{GARCH}(1,1)$ specification.

Li et al. (2002) provide an extensive review of theoretical results for univariate and multivariate time series models with conditional volatility errors, and McAleer (2005) reviews a wide range of univariate and multivariate, conditional and stochastic, models of financial volatility. When the 
daily and weekly world, US and Japanese tourist arrivals data, and the three exchange rate series, display persistence in volatility, as shown in Figures 1-4, it is natural to estimate alternative conditional volatility models.

The GARCH(1,1), GJR(1,1) and $\operatorname{EGARCH}(1,1)$ conditional volatility models have been estimated using monthly and daily tourist arrivals data in several papers, including Chan, Lim and McAleer (2005), Hoti, McAleer and Shareef (2005, 2007), Shareef and McAleer (2005, 2007, 2008), Chang et al. (2009), Chang and McAleer (2009), and Divino and McAleer (2009, 2010). However, these papers have not estimated any spillover effects between tourist arrivals and exchange rates using daily and weekly data, and have not examined world price or price volatility effects. Hence, they have not been able to capture any approximate price or price volatility effects affecting tourism demand, or the effects of temporal and spatial aggregation.

This paper extends the work of Chang et al. (2009) by examining the spillover effects between tourist arrivals and exchange rates, as well as their associated volatilities, using daily data. The effects of spatial aggregation are also examined through the use of approximate world prices and their associated volatility, and the effects of temporal aggregation are examined through the use of daily and weekly data on tourist arrivals and exchange rates.

The conditional volatility literature has been discussed extensively in recent years for a wide range of high frequency data sets (see, for example, Li, Ling and McAleer (2002), McAleer (2005), McAleer, Chan and Marinova (2007), Caporin and McAleer (2009, 2010), and Chang et al. (2009)). Consider the stationary $\operatorname{AR}(1)-G A R C H(1,1)$ model for daily or weekly world, US and Japanese tourist arrivals to Taiwan, $y_{t}$ :

$$
y_{t}=\phi_{1}+\phi_{2} y_{t-1}+\varepsilon_{t}, \quad\left|\phi_{2}\right|<1
$$

for $t=1, \ldots, n$, where the shocks (that is, movements in international tourist arrivals) are given by:

$$
\begin{aligned}
& \varepsilon_{t}=\eta_{t} \sqrt{h_{t}}, \quad \eta_{t} \sim \operatorname{iid}(0,1) \\
& h_{t}=\omega+\alpha \varepsilon_{t-1}^{2}+\beta h_{t-1},
\end{aligned}
$$


and $\omega>0, \alpha \geq 0, \beta \geq 0$ are sufficient conditions to ensure that the conditional variance $h_{t}>0$. The $\operatorname{AR}(1)$ model in equation (1) can easily be extended to univariate or multivariate $\operatorname{ARMA}(p, q)$ processes (for further details, see Ling and McAleer (2003a)). In equation (2), the ARCH (or $\alpha$ ) effect indicates the short run persistence of shocks, while the GARCH (or $\beta$ ) effect indicates the contribution of shocks to long run persistence (namely, $\alpha+\beta$ ). The stationary AR(1)$\operatorname{GARCH}(1,1)$ model can be modified to incorporate a non-stationary $\operatorname{ARMA}(p, q)$ conditional mean and a stationary $\operatorname{GARCH}(r, s)$ conditional variance, as in Ling and McAleer (2003b).

A number of previous papers have discussed that, in equations such as (1) and (2), the parameters are typically estimated by the maximum likelihood method to obtain Quasi-Maximum Likelihood Estimators (QMLE) in the absence of normality of $\eta_{t}$, the conditional shocks (or standardized residuals). The conditional log-likelihood function is given as follows:

$$
\sum_{t=1}^{n} l_{t}=-\frac{1}{2} \sum_{t=1}^{n}\left(\log h_{t}+\frac{\varepsilon_{t}^{2}}{h_{t}}\right) .
$$

The QMLE is efficient only if $\eta_{t}$ is normal, in which case it is the MLE. When $\eta_{t}$ is not normal, adaptive estimation can be used to obtain efficient estimators, although this can be computationally intensive. Ling and McAleer (2003b) investigated the properties of adaptive estimators for univariate non-stationary ARMA models with $\operatorname{GARCH}(r, s)$ errors. The extension to multivariate processes is complicated.

As the GARCH process in equation (2) is a function of the unconditional shocks, it is necessary to examine the moments conditions of $\varepsilon_{t}$. Ling and McAleer (2003a) showed that the QMLE for $\operatorname{GARCH}(p, q)$ is consistent if the second moment of $\varepsilon_{t}$ is finite. Using results from Ling and $\mathrm{Li}$ (1997) and Ling and McAleer (2002a, 2002b), the necessary and sufficient condition for the existence of the second moment of $\varepsilon_{t}$ for $\operatorname{GARCH}(1,1)$ is $\alpha+\beta<1$ and, under normality, the necessary and sufficient condition for the existence of the fourth moment is $(\alpha+\beta)^{2}+2 \alpha^{2}<1$.

Among others, McAleer et al. (2007) discussed that it was established by Elie and Jeantheau (1995) and Jeantheau (1998) that the log-moment condition was sufficient for consistency of the QMLE of a univariate GARCH(p,q) process (see Lee and Hansen (1994) for an analysis of the GARCH(1,1) process), while Boussama (2000) showed that the log-moment condition was sufficient for 
asymptotic normality. Based on these theoretical developments, a sufficient condition for the QMLE of $\operatorname{GARCH}(1,1)$ to be consistent and asymptotically normal is given by the log-moment condition, namely

$$
E\left(\log \left(\alpha \eta_{t}^{2}+\beta\right)\right)<0
$$

However, this condition is not easy to check in practice, even for the $\operatorname{GARCH}(1,1)$ model, as it involves the expectation of a function of a random variable and unknown parameters. Although the sufficient moment conditions for consistency and asymptotic normality of the QMLE for the univariate $\operatorname{GARCH}(1,1)$ model are stronger than their log-moment counterparts, the second moment condition is more straightforward to check. In practice, the log-moment condition in equation (3) would be estimated by the sample mean, with the parameters $\alpha$ and $\beta$, and the standardized residual, $\eta_{t}$, being replaced by their QMLE counterparts.

The effects of positive shocks (or upward movements in daily or weekly international tourist arrivals or exchange rates) on the conditional variance, $h_{t}$, are assumed to be the same as the negative shocks (that is, downward movements in daily or weekly international tourist arrivals or exchange rates) in the symmetric GARCH model. In order to accommodate asymmetric behaviour, Glosten, Jagannathan and Runkle (1992) proposed the GJR model, for which GJR(1,1) is defined as follows:

$$
h_{t}=\omega+\left(\alpha+\gamma I\left(\eta_{t-1}\right)\right) \varepsilon_{t-1}^{2}+\beta h_{t-1},
$$

where $\omega>0, \alpha \geq 0, \alpha+\gamma \geq 0, \beta \geq 0$ are sufficient conditions for $h_{t}>0$, and $I\left(\eta_{t}\right)$ is an indicator variable defined by:

$$
I\left(\eta_{t}\right)= \begin{cases}1, & \varepsilon_{t}<0 \\ 0, & \varepsilon_{t} \geq 0\end{cases}
$$

as $\eta_{t}$ has the same sign as $\varepsilon_{t}$. The indicator variable differentiates between positive and negative shocks of equal magnitude, so that asymmetric effects in the data are captured by the coefficient $\gamma$. 
For data in finance, international finance and energy finance, among others, it is expected that $\gamma \geq 0$ because negative shocks increase risk by increasing the debt to equity ratio, but this interpretation need not hold for daily or weekly international tourist arrivals or exchange rates in the absence of a direct risk interpretation. The asymmetric effect, $\gamma$, measures the contribution of shocks to both short run persistence, $\alpha+\frac{\gamma}{2}$, and to long run persistence, $\alpha+\beta+\frac{\gamma}{2}$. It is not possible for leverage to be present in the GJR model, whereby negative shocks increase volatility and positive shocks of equal magnitude decrease volatility.

The regularity condition for the existence of the second moment for $\operatorname{GJR}(1,1)$ under symmetry of $\eta_{t}$ was shown by Ling and McAleer (2002a) to be:

$$
\alpha+\beta+\frac{1}{2} \gamma<1
$$

while McAleer et al. (2007) showed that the weaker log-moment condition for GJR(1,1) was given by:

$$
E\left(\ln \left[\left(\alpha+\gamma I\left(\eta_{t}\right)\right) \eta_{t}^{2}+\beta\right]\right)<0
$$

which involves the expectation of a function of a random variable and unknown parameters.

Nelson (1991) developed an alternative model to capture asymmetric behaviour in the conditional variance, namely the Exponential GARCH $(\operatorname{EGARCH}(1,1))$ model, which is given as:

$$
\log h_{t}=\omega+\alpha\left|\eta_{t-1}\right|+\gamma \eta_{t-1}+\beta \log h_{t-1}, \quad|\beta|<1
$$

where the parameters $\alpha, \beta$ and $\gamma$ have different interpretations from those in the $\operatorname{GARCH}(1,1)$ and $\operatorname{GJR}(1,1)$ models. If $\gamma=0$, there is no asymmetry, while $\gamma<0$, and $\gamma<\alpha<-\gamma$ are the conditions for leverage to exist, whereby negative shocks increase volatility and positive shocks of equal magnitude decrease volatility. 
As noted in McAleer et al. (2007), for example, there are some important differences between EGARCH and the previous two models, GARCH and GJR, as follows: (i) EGARCH is a model of the logarithm of the conditional variance, which implies that no restrictions on the parameters are required to ensure $h_{t}>0$; (ii) moment conditions are required for the GARCH and GJR models as they are dependent on lagged unconditional shocks, whereas EGARCH does not require moment conditions to be established as it depends on lagged conditional shocks (or standardized residuals); (iii) Shephard (1996) observed that $|\beta|<1$ is likely to be a sufficient condition for consistency of QMLE for EGARCH(1,1); (iv) as the standardized residuals appear in equation (7), $|\beta|<1$ would seem to be a sufficient condition for the existence of moments; and (v) in addition to being a sufficient condition for consistency, $|\beta|<1$ is also likely to be sufficient for asymptotic normality of the QMLE of EGARCH(1,1).

EGARCH also captures asymmetries differently from GJR. The parameters $\alpha$ and $\gamma$ in EGARCH(1,1) represent the magnitude (or size) and sign effects of the standardized residuals, respectively, on the conditional variance, whereas $\alpha$ and $\alpha+\gamma$ represent the effects of positive and negative shocks of equal magnitude, respectively, on the conditional variance in $\operatorname{GJR}(1,1)$.

\section{Heterogeneous Models and Empirical Analysis}

As discussed in Chang et al. (2009), the Heterogenous Autoregressive (HAR) model was proposed by Corsi (2009) as an alternative to model and forecast realized volatilities, and is inspired by the Heterogenous Market Hypothesis of Muller, Dacorogna, Dav, Olsen, Pictet, and Ward (1993) and the asymmetric propagation of volatility between long and short horizons. Corsi (2009) showed that the actions of different types of market participants could lead to a restricted autoregressive model with the feature of considering volatilities realized over different time horizons. The heterogeneity of the model derives from the fact that different autoregressive structures are present at each time scale (for further details, see McAleer and Medeiros (2008)).

Although HAR models cannot reproduce the theoretical hyperbolic decay rates associated with fractionally integrated (or long memory) time series models, they can nevertheless approximate quite accurately and parsimoniously the slowly decaying correlations associated with such long memory models. For this reason, HAR models may be interpreted as simple restricted approximations to long memory models. Alternative HAR models will be used to model 
international tourist arrivals to Taiwan from the world, USA and Japan, together with three widely used univariate conditional volatility models, namely GARCH, GJR and EGARCH, as discussed in the previous section.

The alternative $\operatorname{HAR}(h)$ models to be estimated to approximate long memory for world, US and Japanese tourist arrivals to Taiwan $\left(y_{t}\right)$, and the corresponding exchange rates $\left(x_{t}\right)$, are based on the following data transformations:

$$
\begin{aligned}
& y_{t, h}=\frac{y_{t}+y_{t-1}+y_{t-2}+\ldots+y_{t-h+1}}{h} \\
& x_{t, h}=\frac{x_{t}+x_{t-1}+x_{t-2}+\ldots+x_{t-h+1}}{h}
\end{aligned}
$$

where typical values of $h$ in equations (8) and (9) are 1 for daily data, 7 for weekly data, and 28 for monthly data.

In the empirical application below, the three HAR models for world, US and Japanese daily tourist arrivals to Taiwan are given, respectively, as:

$$
\begin{aligned}
& y_{t}=\phi_{1}+\phi_{21} y_{t-1}+\phi_{22} x_{t-1}+\varepsilon_{t} \\
& y_{t}=\phi_{1}+\phi_{21} y_{t-1}+\phi_{22} x_{t-1}+\phi_{31} y_{t-1,7}+\phi_{32} x_{t-1,7}+\varepsilon_{t} \\
& y_{t}=\phi_{1}+\phi_{21} y_{t-1}+\phi_{22} x_{t-1}+\phi_{31} y_{t-1,7}+\phi_{32} x_{t-1,7}+\phi_{41} y_{t-1,28}+\phi_{42} x_{t-1,28}+\varepsilon_{t}
\end{aligned}
$$

where the lagged explanatory variables involve HAR transformations of the daily tourist arrivals and corresponding daily exchange rates. Under temporal aggregation, the two HAR models for world, US and Japanese weekly tourist arrivals to Taiwan are given, respectively, as:

$$
\begin{aligned}
& y_{t}=\phi_{1}+\phi_{21} y_{t-1}+\phi_{22} x_{t-1}+\varepsilon_{t} \\
& y_{t}=\phi_{1}+\phi_{21} y_{t-1}+\phi_{22} x_{t-1}+\phi_{31} y_{t-1,4}+\phi_{32} x_{t-1,4}+\varepsilon_{t}
\end{aligned}
$$

where the lagged explanatory variables involve HAR transformations of the weekly tourist arrivals and corresponding weekly exchange rates. 
The models in equations (10)-(12) will be referred to as the $\operatorname{HAR}(1), \operatorname{HAR}(1,7)$ and $\operatorname{HAR}(1,7,28)$ models, respectively, and those in equations (13)-(14) as the $\operatorname{HAR}(1)$ and $\operatorname{HAR}(1,4)$ models, respectively. The two sets of models in (10)-(12) and (13)-(14) enable an assessment of the effects of temporal aggregation from the daily to the weekly data frequency. Moreover, a comparison of the model of world tourist arrivals to Taiwan with those of US and Japanese tourist arrivals to Taiwan enable an examination of spatial aggregation effects on the HAR estimates, short and long run persistence of shocks on tourist arrivals, the exchange rate effects, and the empirical regularity conditions.

The estimated conditional mean and conditional volatility models for the world, Japan and USA are given for the HAR(1) model in Tables 2-4 for daily data and in Tables 5-7 for weekly data (the results for the $\operatorname{HAR}(1,7)$ and $\operatorname{HAR}(1,7,28)$ models for daily data, and $\operatorname{HAR}(1,4)$ model for weekly data, are available on request). Tables $2 \mathrm{a}-7 \mathrm{a}$ incorporate exchange rates as the approximate price variable, whereas Tables $2 b-7 b$ include exchange rate volatility as the approximate price variable. These alternative specifications permit an examination of whether exchange rates or their respective volatilities are able to capture the approximate price effects of exchange rates on tourist arrivals to Taiwan.

The method used in estimation was the Marquardt algorithm. The conditional mean estimates in Tables 2-7 show that the HAR(1) estimates for daily and weekly data are all statistically significant. Thus, the approximate long memory properties of world, Japanese and US tourist arrivals to Taiwan would seem to be captured adequately through the statistical significance of the approximate long memory variables.

As the second moment conditions for the $\operatorname{GARCH}(1,1)$ and $\operatorname{GJR}(1,1)$ models are less than unity in each case, the log-moment conditions are also necessarily satisfied. Thus, the regularity conditions are satisfied, and hence the QMLE are consistent and asymptotically normal, and inferences are valid. The $\operatorname{EGARCH}(1,1)$ model is based on the standardized residuals, so the regularity condition is satisfied if $|\beta|<1$, and hence the QMLE are consistent and asymptotically normal (see, for example, McAleer et al. (2007)).

The approximate price and price volatility effects tend to be different, with the exchange rate typically having the expected negative impact on tourist arrivals to Taiwan, whereas exchange rate 
volatility can have positive or negative effects on tourist arrivals to Taiwan. For daily data, the exchange rate effect is consistently negative and significant in Tables $2 a-4 a$, whereas the exchange rate volatility effect is positive and significant for world tourist arrivals to Taiwan (Table 2b), but negative and significant for tourist arrivals to Taiwan from Japan and the USA (Tables 3b-4b). For weekly data, the exchange rate effect is negative though insignificant for world tourist arrivals to Taiwan (Table 5a), but negative and significant for tourist arrivals to Taiwan from Japan and the USA (Tables 6a-7a), whereas exchange rate volatility is not significant for world and Japanese tourist arrivals to Taiwan (Tables 5b-6b) but is negative and significant for tourist arrivals from the USA (Table 7b).

The GARCH(1,1) estimates in Tables 2a-7a for the HAR(1) models of world, Japanese and US tourist arrivals to Taiwan suggest that the short and long run persistence of shocks for daily data lie between $(0.220,0.261)$ and $(0.243,0.429)$, respectively, for the world, between $(0.256,0.326)$ and $(0.418,0.489)$, respectively, for Japan, and between $((0.051,0.054)$ and $(0.980,0,984)$, respectively, for USA. The corresponding short and long run persistence of shocks for weekly data lie between $(0.348,0.411)$ and $(0.441,0.541)$, respectively, for the world, between $(0.104,0.108)$ and $(0.854$, $0.861)$, respectively, for Japan, and between $((0.343,0.352)$ and $(0.579,0.650)$, respectively, for USA. Thus, the range of estimates for the short and long run persistence of shocks differs according to the world and the two leading tourism sources to Taiwan, which reflects the importance of spatial aggregation, as well as the data frequency, which reflects the importance of temporal aggregation.

If positive and negative shocks to world, Japanese and US tourist arrivals to Taiwan of a similar magnitude are treated asymmetrically, this can be evaluated in the GJR(1,1) model. Asymmetry (though not leverage) was found in 7 of 9 cases for daily data for the world, Japan and USA, and asymmetry (though not leverage) was found in 4 of 6 cases for weekly data. Therefore, shocks to world, Japanese and US tourist arrivals to Taiwan can be interpreted as risk associated with the corresponding tourist arrivals. Although asymmetry is observed for the HAR(1) model for the world, Japan and USA for daily data, and for the HAR(1) model for the world and USA for weekly data, there is no evidence of leverage. Moreover, the three HAR models suggest asymmetry for Japan using daily data, but changes to symmetry for Japan using two models for weekly data. Thus, these empirical results show that a determination of symmetry or asymmetry arising from the conditional volatility models is sensitive to the temporal aggregation of daily to weekly data. 
As the second moment condition, $\alpha+\beta+\frac{1}{2} \gamma<1$, is typically satisfied, the log-moment condition is necessarily satisfied, so that the QMLE for the $\operatorname{GJR}(1,1)$ model are consistent and asymptotically normal. Therefore, statistical inference using the asymptotic normal distribution is valid, and the asymmetric GJR(1,1) estimates are statistically significant.

The interpretation of the EGARCH model is in terms of the logarithm of volatility. For daily and weekly world, Japanese and US tourist arrivals to Taiwan, the $\operatorname{EGARCH}(1,1)$ estimates were generally statistically significant for the various HAR models, with the size effect, $\alpha$, and sign effect, $\gamma$, typically being significant. The coefficient of the lagged dependent variable, $\beta$, is estimated to be less than unity, which suggests that the statistical properties of the QMLE for $\operatorname{EGARCH}(1,1)$ will be consistent and asymptotically normal.

The world price and exchange rate effects are always negative for the HAR(1) model for daily and weekly data, and are also generally negative for the $\operatorname{HAR}(1,7)$ and $\operatorname{HAR}(1,7,28)$ models for daily data and HAR $(1,4)$ model for weekly data. The expected negative price and exchange rate effects generally do not change with temporal aggregation, although the exchange rate volatility effects on tourist arrivals were not consistently positive or negative.

In summary, the QMLE for the $\operatorname{GARCH}(1,1), \operatorname{GJR}(1,1)$ and $\operatorname{EGARCH}(1,1)$ models for daily and weekly world, Japanese and US tourist arrivals to Taiwan are statistically adequate and have sensible interpretations. The empirical results also show that the volatility in the shocks to daily and weekly world, Japanese and US tourist arrivals to Taiwan can be sensitive to the long memory nature of the conditional mean specifications.

\section{Concluding Remarks}

Although tourism is not yet one of the most important service industries in Taiwan, tourist arrivals from Japan and USA, the two most important source countries for Taiwan, reflect an increasing demand for short and long haul tourist travel. World tourist arrivals to Taiwan have been growing steadily, and reflect the spatial aggregation of numerous tourism source countries. However, there is significant room for improvement in tourism receipts from the various tourism source countries. 
The potential negative impacts of mass tourism on the environment, and hence on future world, Japanese and US tourism demand, must be managed appropriately. In order to manage such tourism growth, it is necessary to model adequately world, Japanese and US tourist arrivals and their associated volatility. As the exchange rate allows approximate daily price effects on Japanese and US tourism arrivals to Taiwan to be captured, it is also necessary to analyse the Yen / New Taiwan \$ and US\$ / New Taiwan \$ exchange rates, and the world price, as well as their associated volatilities.

The paper examined daily and weekly world, Japanese and US tourist arrivals to Taiwan from 1 January 1990 to 31 December 2008, and the world price and Yen / New Taiwan \$ and US\$ / New Taiwan \$ exchange rates. The Heterogeneous Autoregressive (HAR) model was used to capture the approximate long memory properties in the tourist arrivals series. The empirical results showed that the time series of world, Japanese and US tourist arrivals to Taiwan, and the world price and two exchange rates, were stationary. In addition, the estimated symmetric and asymmetric conditional volatility models, specifically the widely used GARCH, GJR and EGARCH models, all fit the data extremely well.

The estimated models were able to account for the higher volatility persistence that was observed at the end of the sample period, due primarily to the global financial crisis. It was also found that the approximate price and price volatility effects tended to be different, with the exchange rate typically having the expected negative impact on tourist arrivals to Taiwan, whereas exchange rate volatility displayed positive and negative effects on tourist arrivals to Taiwan, depending on the source of the international tourists.

The empirical second moment condition also generally supported the statistical adequacy of the models of world, Japanese and US tourist arrivals to Taiwan, so that statistical inferences were valid. Moreover, the estimates resembled those arising from financial time series data, with both short and long run persistence of shocks, and asymmetric effects of positive and negative shocks of equal magnitude to volatility. Although asymmetry was observed for the HAR models using daily and weekly data, there was no evidence of leverage. Overall, volatility could be interpreted as risk associated with shocks to world, Japanese and US tourist arrivals to Taiwan.

With regard to the effects of temporal and spatial aggregation, it was found that HAR effects did not seem to be sensitive to temporal aggregation, a determination of symmetry or asymmetry arising 
from the conditional volatility models was sensitive to the temporal aggregation of daily to weekly data, the expected negative price and exchange rate effects generally did not change with temporal aggregation, and the range of estimates for the short and long run persistence of shocks were different for the world, Japan and USA. Thus, both spatial aggregation and the data frequency, or temporal aggregation, were found to be important for estimating the dynamic effects of world prices and exchange rates, and their respective volatilities, on world, Japanese and US tourist arrivals to Taiwan.

For policy purposes, these empirical results suggest that an arbitrary choice of data frequency or spatial aggregation will not lead to robust findings as they are generally not independent of the level of aggregation used. Thus, a careful analysis of different levels of temporal and spatial aggregation needs to be undertaken to obtain sensible estimates, regularity conditions, short and long run persistence of shocks to tourist arrivals, asymmetry and leverage effects, and the generally negative effects of the world price and exchange rates, though not necessarily of their associated volatilities, on international tourist arrivals. 


\section{References}

Bollerslev, T. (1986) "Generalised autoregressive conditional heteroscedasticity", Journal of Econometrics, Vol. 31, pp. 307-327.

Boussama, F. (2000) "Asymptotic normality for the quasi-maximum likelihood estimator of a GARCH model", Comptes Rendus de l'Academie des Sciences, Serie I, 331, pp. 81-84 (in French).

Caporin, M., M. McAleer (2009) "Do we really need both BEKK and DCC? A tale of two covariance models", Available at SSRN: http://ssrn.com/abstract=1338190.

Caporin, M., M. McAleer (2010) "Do we really need both BEKK and DCC? A tale of two multivariate GARCH models", to appear in Journal of Economic Surveys, Available at SSRN: http://ssrn.com/abstract=1549167.

Chan, F., C. Lim and M. McAleer (2005) "Modelling multivariate international tourism demand and volatility", Tourism Management, Vol. 26, pp. 459-471.

Chang, C.-L. and M. McAleer (2009) "Daily tourist arrivals, exchange rates and volatility for Korea and Taiwan”, Korean Economic Review, Vol. 25, pp. 241-267.

Chang, C.-L., M. McAleer and D. Slottje (2009) "Modelling international tourist arrivals and volatility: An application to Taiwan”, in D. Slottje (ed.), Quantifying Consumer Preferences, Contributions to Economic Analysis Series, Volume 288, Emerald Group Publishing, pp. 303332. Available at SSRN: http://ssrn.com/abstract=1355108.

Corsi, F. (2009) “A simple approximate long-memory model of realized volatility”, Journal of Financial Econometrics, Vol. 7, pp. 174-196.

Dickey, D.A. and W. A. Fuller (1979) "Distribution of the estimators for autoregressive time series with a unit root", Journal of the American Statistical Association, Vol. 74, pp. 427-431.

Dickey, D.A. and W. A. Fuller (1981) "Likelihood ratio statistics for autoregressive time series with a unit root", Econometrica, Vol. 49, pp. 1057-1072.

Divino, J.A. and M. McAleer (2009) "Modelling and forecasting sustainable international tourism demand for the Brazilian Amazon”, Environmental Modelling \& Software, Vol. 24, pp. 14111419. 
Divino, J.A. and M. McAleer (2010) "Modelling and forecasting daily international mass tourism to Peru", Tourism Management, Vol. 31, pp. 846-854.

Elie, L., T. Jeantheau (1995) "Consistency in heteroskedastic models", Comptes Rendus de l’Académie des Sciences, Série I, 320, pp. 1255-1258 (in French).

Engle, R.F. (1982) “Autoregressive conditional heteroscedasticity with estimates of the variance of United Kingdom inflation”, Econometrica, Vol. 50, pp. 987-1007.

Glosten, L., R. Jagannathan and D. Runkle (1992) "On the relation between the expected value and volatility of nominal excess return on stocks”, Journal of Finance, Vol. 46, pp. 1779-1801.

Hoti, S., M. McAleer and R. Shareef, (2005) "Modelling country risk and uncertainty in small island tourism economies", Tourism Economics, Vol. 11, pp. 159-183.

Hoti, S., M. McAleer and R. Shareef (2007) "Modelling international tourism and country risk spillovers for Cyprus and Malta”, Tourism Management, Vol. 28, pp. 1472-84.

Jeantheau, T. (1998) "Strong consistency of estimators for multivariate ARCH models", Econometric Theory, Vol. 14, pp. 70-86.

Lee, S.W. and B.E. Hansen (1994) “Asymptotic theory for the GARCH(1,1) quasi-maximum likelihood estimator", Econometric Theory, Vol. 10, pp. 29-52.

Li, W.K., S. Ling and M. McAleer (2002) "Recent theoretical results for time series models with GARCH errors", Journal of Economic Surveys, 16, 245-269. Reprinted in M. McAleer and L. Oxley (eds.), Contributions to Financial Econometrics: Theoretical and Practical Issues, Blackwell, Oxford, pp. 9-33.

Ling, S. and W.K. Li (1997) "On fractionally integrated autoregressive moving-average models with conditional heteroskedasticity", Journal of the American Statistical Association, Vol. 92, pp. 1184-1194.

Ling, S. and M. McAleer (2002a) "Stationarity and the existence of moments of a family of GARCH processes”, Journal of Econometrics, Vol. 106, pp. 109-117.

Ling, S. and M. McAleer (2002b) "Necessary and sufficient moment conditions for the GARCH(r,s) and asymmetric power GARCH(r,s) models", Econometric Theory, Vol. 18, pp. 722-729. 
Ling, S. and M. McAleer (2003a) "Asymptotic theory for a vector ARMA-GARCH model", Econometric Theory, Vol. 19, pp. 278-308.

Ling, S and M. McAleer (2003b) "On adaptive estimation in nonstationary ARMA models with GARCH errors", Annals of Statistics, Vol. 31, pp. 642-674.

McAleer, M. (2005) “Automated inference and learning in modeling financial volatility", Econometric Theory, Vol. 21, pp. 232-261.

McAleer, M. (2009) "The Ten Commandments for optimizing value-at-risk and daily capital charges", Journal of Economic Surveys, Vol. 23, pp. 831-849.

McAleer, M., F. Chan and D. Marinova (2007) "An econometric analysis of asymmetric volatility: theory and application to patents", Journal of Econometrics, Vol. 139, pp. 259-284.

McAleer, M., J.-A. Jiménez-Martin and T. Perez Amaral (2009a) "Has the Basel II Accord encouraged risk management during the 2008-09 financial crisis?", Available at SSRN: http://ssrn.com/abstract=1397239.

McAleer, M., J.-A . Jiménez-Martin and T. Perez Amaral (2009b) "Optimal risk management before, during and after the 2008-09 financial crisis", Available at SSRN: http://ssrn.com/abstract=1473191.

McAleer, M., J.-A. Jiménez-Martin and T. Perez Amaral (2010) "What happened to risk management during the 2008-09 financial crisis?", in R.W. Kolb (ed.), Lessons from the Financial Crisis: Causes, Consequences, and Our Economic Future, Wiley, New York, 2010, pp. 307-316, Available at SSRN: http://ssrn.com/abstract=1442034.

McAleer, M., T. Perez Amaral and J.-A. Jiménez-Martin (2009) "A decision rule to minimize daily capital charges in forecasting value-at-risk", Journal of Forecasting, Vol. 29, No. 7, pp. 617634.

McAleer, M., and M. Medeiros (2008) "A multiple regime smooth transition heterogeneous autoregressive model for long memory and asymmetries", Journal of Econometrics, Vol.147, No. 1, pp. 104-119.

Muller, U. M. Dacorogna, R. Dav, R. Olsen, O. Pictet and J. Ward (1993) "Fractals and intrinsic time - a challenge to econometricians", in Proceedings of the XXXIXth International AEA Conference on Real Time Econometrics. 
Nelson, D.B. (1991) "Conditional heteroscedasticity in asset returns: a new approach", Econometrica, Vol. 59, pp. 347-370.

Phillips, P.C.B. and P. Perron (1988) “Testing for a unit root in time series regression”, Biometrika, Vol. 75, pp. 335-346.

Shareef, R. and M. McAleer (2005) "Modelling international tourism demand and volatility in small island tourism economies", International Journal of Tourism Research, Vol. 7, pp. 313-333.

Shareef, R. and M. McAleer (2007) "Modelling the uncertainty in international tourist arrivals to the Maldives”, Tourism Management, Vol. 28, pp. 23-45.

Shareef, R. and M. McAleer (2008) "Modelling international tourism demand and uncertainty in Maldives and Seychelles: a portfolio approach”, Mathematics and Computers in Simulation, Vol. 78, pp. 459-68.

Shephard, N. (1996) "Statistical aspects of ARCH and stochastic volatility, in O.E. BarndorffNielsen, D.R. Cox and D.V. Hinkley (eds.)", Statistical Models in Econometrics, Finance and Other Fields, Chapman \& Hall, London, pp. 1-67. 
Table 1. Unit Root Tests

\begin{tabular}{|c|c|c|c|c|}
\hline Variables & $\begin{array}{r}\text { ADF } \\
Z=\{1\}\end{array}$ & $\begin{array}{c}\text { PP } \\
Z=\{1\}\end{array}$ & $\begin{array}{l}\text { ADF } \\
Z=\{1, t\}\end{array}$ & $\begin{array}{c}\text { PP } \\
Z=\{1, t\}\end{array}$ \\
\hline Daily World Tourist Arrivals to Taiwan & $-3.164 *$ & $-58.939 * *$ & $-5.445^{* *}$ & $-78.257 * *$ \\
\hline Daily Japanese Tourist Arrivals to Taiwan & $-5.491 * *$ & $-65.306 * *$ & $-6.330 * *$ & $-64.594 * *$ \\
\hline Daily US Tourist Arrivals to Taiwan & $-4.648 * *$ & $-71.519 * *$ & $-7.100 * *$ & $-81.346^{* *}$ \\
\hline Variables & $\begin{array}{c}\text { ADF } \\
Z=\{1\}\end{array}$ & $\begin{array}{l}\text { PP } \\
Z=\{1\}\end{array}$ & $\begin{array}{c}\text { ADF } \\
Z=\{1, t\}\end{array}$ & $\begin{array}{c}P P \\
Z=\{1, t\}\end{array}$ \\
\hline Weekly World Tourist Arrivals to Taiwan & -2.161 & $-8.825 * *$ & $-4.252 * *$ & $-16.211^{* *}$ \\
\hline Weekly Japanese Tourist Arrivals to Taiwan & $-3.540 * *$ & $-19.530 * *$ & $-4.434 * *$ & $-21.092 * *$ \\
\hline Weekly US Tourist Arrivals to Taiwan & $-4.648 * *$ & $-10.358 * *$ & $-8.135^{* *}$ & $-14.719 * *$ \\
\hline
\end{tabular}

Notes: The critical values for the ADF test are $-3.43(-2.86)$ at the $1 \%(5 \%)$ level when $Z=\{1\}$, and $-3.95(-3.41)$ at the $1 \%(5 \%)$ level when $Z=\{1, \mathrm{t}\}$. The critical values for the PP test are $-3.43(-2.86)$ at the $1 \%(5 \%)$ level when $Z=\{1\}$, and $-3.95(-3.41)$ at the $1 \%(5 \%)$ level when $Z=\{1, t\}$.

$* *$ and $*$ denote the null hypothesis of a unit root is rejected at the $1 \%$ and $5 \%$ levels, respectively. 
Table 2a: HAR(1) Conditional Mean and Conditional Volatility Models for World Daily Tourist Arrivals to Taiwan, with HAR(1) Exchange Rates

\begin{tabular}{|c|c|c|c|}
\hline Parameters & GARCH & GJR & EGARCH \\
\hline$\phi_{1}$ & $\begin{array}{c}1393.2 * * * \\
(122.1)\end{array}$ & $\begin{array}{c}1300 * * * \\
(118.6)\end{array}$ & $\begin{array}{c}1303.6 * * * \\
(118.4)\end{array}$ \\
\hline$\phi_{21}$ & $\begin{array}{c}0.816^{* * * *} \\
(0.008)\end{array}$ & $\begin{array}{c}0.824 * * * \\
(0.007)\end{array}$ & $\begin{array}{c}0.830 * * * \\
(0.007)\end{array}$ \\
\hline$\phi_{22}$ & $\begin{array}{c}-3.178 * * * \\
(1.047)\end{array}$ & $\begin{array}{c}-3.082 * * * \\
(1.007)\end{array}$ & $\begin{array}{c}-3.620 * * * \\
(0.999)\end{array}$ \\
\hline$\omega$ & $\begin{array}{c}899965 * * * \\
(29091)\end{array}$ & $\begin{array}{c}852835 * * * \\
(29755)\end{array}$ & $\begin{array}{c}11.317 * * * \\
(0.555)\end{array}$ \\
\hline GARCH/GJR $\alpha$ & $\begin{array}{c}0.220 * * * \\
(0.013)\end{array}$ & $\begin{array}{c}0.135 * * * \\
(0.009)\end{array}$ & -- \\
\hline GARCH/GJR $\beta$ & $\begin{array}{c}0.023 \\
(0.022)\end{array}$ & $\begin{array}{l}0.044^{*} \\
(0.025)\end{array}$ & -- \\
\hline GJR $\gamma$ & -- & $\begin{array}{c}0.259 * * * \\
(0.038)\end{array}$ & -- \\
\hline EGARCH $\alpha$ & -- & -- & $\begin{array}{c}0.438 * * * \\
(0.020)\end{array}$ \\
\hline EGARCH $\gamma$ & -- & -- & $\begin{array}{c}-0.116^{* * *} \\
(0.016)\end{array}$ \\
\hline EGARCH $\beta$ & -- & -- & $\begin{array}{c}0.164 * * * \\
(0.040)\end{array}$ \\
\hline \multicolumn{4}{|l|}{ Diagnostics } \\
\hline AIC & 16.776 & 16.769 & 16.769 \\
\hline $\mathrm{BIC}$ & 16.782 & 16.777 & 16.776 \\
\hline $\begin{array}{l}\text { Jarque-Bera } \\
\text { [p-value] }\end{array}$ & $\begin{array}{l}1828.80 \\
{[0.000]}\end{array}$ & $\begin{array}{l}1285.23 \\
{[0.000]}\end{array}$ & $\begin{array}{l}1306.88 \\
{[0.000]}\end{array}$ \\
\hline $\begin{array}{l}\text { Causality } t \text { test } \\
\text { [p-value] }\end{array}$ & $\begin{array}{l}-3.036 \\
{[0.002]}\end{array}$ & $\begin{array}{l}-3.059 \\
{[0.002]}\end{array}$ & $\begin{array}{l}-3.625 \\
{[0.0003]}\end{array}$ \\
\hline
\end{tabular}

Notes: The dependent variable is world daily tourist arrivals to Taiwan. Numbers in parentheses are standard errors. The log-moment condition is necessarily satisfied as the second moment condition is satisfied. AIC and BIC denote the Akaike Information Criterion and Schwarz Bayesian Information Criterion, respectively. $* * *$ and $*$ denote the estimated coefficients are statistically significant at the $1 \%$ and $10 \%$ levels, respectively. 
Table 2b: HAR(1) Conditional Mean and Conditional Volatility Models for World Daily Tourist Arrivals to Taiwan, with HAR(1) Exchange Rate Volatility

\begin{tabular}{|c|c|c|c|}
\hline Parameters & GARCH & GJR & EGARCH \\
\hline$\phi_{1}$ & $\begin{array}{c}1099.1 * * * \\
(46.34)\end{array}$ & $\begin{array}{c}1014.4 * * * \\
(45.57)\end{array}$ & $\begin{array}{c}986.6 * * * \\
(44.58)\end{array}$ \\
\hline$\phi_{21}$ & $\begin{array}{c}0.805^{* * * *} \\
(0.007)\end{array}$ & $\begin{array}{c}0.813^{* * * *} \\
(0.007)\end{array}$ & $\begin{array}{c}0.817 * * * \\
(0.007)\end{array}$ \\
\hline$\phi_{22}$ & $\begin{array}{c}0.591 * * * \\
(0.070)\end{array}$ & $\begin{array}{c}0.568 * * * \\
(0.069)\end{array}$ & $\begin{array}{c}0.543 * * * \\
(0.069)\end{array}$ \\
\hline$\omega$ & $\begin{array}{c}885989 * * * \\
(28341)\end{array}$ & $\begin{array}{l}850856 * * * \\
(28768.81)\end{array}$ & $\begin{array}{c}11.417 * * * \\
(0.565)\end{array}$ \\
\hline GARCH/GJR $\alpha$ & $\begin{array}{c}0.225^{* * *} \\
(0.013)\end{array}$ & $\begin{array}{c}0.142 * * * \\
(0.010)\end{array}$ & -- \\
\hline GARCH/GJR $\beta$ & $\begin{array}{c}0.025 \\
(0.021)\end{array}$ & $\begin{array}{c}0.036 \\
(0.023332)\end{array}$ & -- \\
\hline GJR $\gamma$ & - & $\begin{array}{c}0.255^{* * *} \\
(0.038)\end{array}$ & -- \\
\hline EGARCH $\alpha$ & -- & -- & $\begin{array}{c}0.436 * * * \\
(0.020)\end{array}$ \\
\hline EGARCH $\gamma$ & -- & -- & $\begin{array}{c}-0.109 * * * \\
(0.016)\end{array}$ \\
\hline EGARCH $\beta$ & -- & -- & $\begin{array}{c}0.157 * * * \\
(0.041)\end{array}$ \\
\hline \multicolumn{4}{|l|}{ Diagnostics } \\
\hline AIC & 16.768 & 16.762 & 16.763 \\
\hline BIC & 16.774 & 16.769 & 16.770 \\
\hline $\begin{array}{l}\text { Jarque-Bera } \\
\text { [p-value] }\end{array}$ & $\begin{array}{l}1014.07 \\
{[0.000]}\end{array}$ & $\begin{array}{l}1242.25 \\
{[0.000]}\end{array}$ & $\begin{array}{l}1260.23 \\
{[0.000]}\end{array}$ \\
\hline $\begin{array}{l}\text { Causality } t \text { test } \\
\text { [p-value] }\end{array}$ & $\begin{array}{c}8.420 \\
{[0.000]}\end{array}$ & $\begin{array}{c}8.244 \\
{[0.000]}\end{array}$ & $\begin{array}{c}7.916 \\
{[0.000]}\end{array}$ \\
\hline
\end{tabular}

Notes: The dependent variable is world daily tourist arrivals to Taiwan. Numbers in parentheses are standard errors. The log-moment condition is necessarily satisfied as the second moment condition is satisfied.

AIC and BIC denote the Akaike Information Criterion and Schwarz Bayesian Information Criterion, respectively. *** denotes the estimated coefficients are statistically significant at the $1 \%$ levels.

The volatility of the exchange rate is taken to be the squared deviation from the mean exchange rate. 
Table 3a: HAR(1) Conditional Mean and Conditional Volatility Models for Japanese Daily Tourist Arrivals to Taiwan, with HAR(1) Exchange Rates

\begin{tabular}{|c|c|c|c|}
\hline Parameters & GARCH & GJR & EGARCH \\
\hline$\phi_{1}$ & $\begin{array}{c}1126.3^{* * * *} \\
(53.04)\end{array}$ & $\begin{array}{c}1094.2 * * * \\
(52.30)\end{array}$ & $\begin{array}{c}1101.1 * * * \\
(53.33)\end{array}$ \\
\hline$\phi_{21}$ & $\begin{array}{c}0.672 * * * \\
(0.009)\end{array}$ & $\begin{array}{c}0.682 * * * \\
(0.009)\end{array}$ & $\begin{array}{c}0.674 * * * \\
(0.009)\end{array}$ \\
\hline$\phi_{22}$ & $\begin{array}{c}-82.00 * * * \\
(11.486)\end{array}$ & $\begin{array}{c}-74.53 * * * \\
(11.59)\end{array}$ & $\begin{array}{c}-71.459 * * * \\
(11.83)\end{array}$ \\
\hline$\omega$ & $\begin{array}{c}246509 * * * \\
(13137)\end{array}$ & $\begin{array}{c}222585 * * * \\
(12750)\end{array}$ & $\begin{array}{c}5.372 * * * \\
(0.392)\end{array}$ \\
\hline GARCH/GJR $\alpha$ & $\begin{array}{c}0.256 * * * \\
(0.015)\end{array}$ & $\begin{array}{c}0.363 * * * \\
(0.024)\end{array}$ & -- \\
\hline GARCH/GJR $\beta$ & $\begin{array}{c}0.162 * * * \\
(0.033)\end{array}$ & $\begin{array}{c}0.242 * * * \\
(0.033)\end{array}$ & -- \\
\hline GJR $\gamma$ & -- & $\begin{array}{c}-0.284 * * * \\
(0.026)\end{array}$ & -- \\
\hline EGARCH $\alpha$ & -- & -- & $\begin{array}{c}0.326 * * * \\
(0.018)\end{array}$ \\
\hline EGARCH $\gamma$ & -- & -- & $\begin{array}{c}0.160 * * * \\
(0.012)\end{array}$ \\
\hline EGARCH $\beta$ & -- & -- & $\begin{array}{c}0.563 * * * \\
(0.031)\end{array}$ \\
\hline \multicolumn{4}{|l|}{ Diagnostics } \\
\hline AIC & 15.726 & 15.713 & 15.719 \\
\hline BIC & 15.732 & 15.720 & 15.726 \\
\hline $\begin{array}{l}\text { Jarque-Bera } \\
\text { [p-value] }\end{array}$ & $\begin{array}{c}694.00 \\
{[0.000]}\end{array}$ & $\begin{array}{l}599.97 \\
{[0.000]}\end{array}$ & $\begin{array}{l}580.31 \\
{[0.000]}\end{array}$ \\
\hline $\begin{array}{l}\text { Causality } t \text { test } \\
\text { [p-value] }\end{array}$ & $\begin{array}{l}-7.139 \\
{[0.000]}\end{array}$ & $\begin{array}{c}-6.430 \\
{[0.000]}\end{array}$ & $\begin{array}{l}-6.043 \\
{[0.000]}\end{array}$ \\
\hline
\end{tabular}

Notes: The dependent variable is Japanese daily tourist arrivals to Taiwan. Numbers in parentheses are standard errors. The log-moment condition is necessarily satisfied as the second moment condition is satisfied.

$\mathrm{AIC}$ and BIC denote the Akaike Information Criterion and Schwarz Bayesian Information Criterion, respectively.

*** denotes the estimated coefficients are statistically significant at the $1 \%$ level . 
Table 3b: HAR(1) Conditional Mean and Conditional Volatility Models for Japanese Daily Tourist Arrivals to Taiwan, with HAR(1) Exchange Rate Volatility

\begin{tabular}{|c|c|c|c|}
\hline Parameters & GARCH & GJR & EGARCH \\
\hline$\phi_{1}$ & $\begin{array}{c}794.86 * * * \\
(24.26)\end{array}$ & $\begin{array}{c}798.06 * * * \\
(24.01)\end{array}$ & $\begin{array}{c}810.57 * * * \\
(23.59)\end{array}$ \\
\hline$\phi_{21}$ & $\begin{array}{c}0.682 * * * \\
(0.009)\end{array}$ & $\begin{array}{c}0.690 * * * \\
(0.009)\end{array}$ & $\begin{array}{c}0.684 * * * \\
(0.009)\end{array}$ \\
\hline$\phi_{22}$ & $\begin{array}{c}-31.02 * * * \\
(10.26)\end{array}$ & $\begin{array}{c}-31.25^{* * *} \\
(10.25)\end{array}$ & $\begin{array}{c}-28.52 * * * \\
(10.91)\end{array}$ \\
\hline$\omega$ & $\begin{array}{c}246268 * * * \\
(13679)\end{array}$ & $\begin{array}{c}216135 * * * \\
(12895)\end{array}$ & $\begin{array}{c}4.754 * * * \\
(0.367)\end{array}$ \\
\hline GARCH/GJR $\alpha$ & $\begin{array}{c}0.244 * * * \\
(0.0149)\end{array}$ & $\begin{array}{c}0.352 * * * \\
(0.023)\end{array}$ & -- \\
\hline GARCH/GJR $\beta$ & $\begin{array}{c}0.175 * * * \\
(0.034)\end{array}$ & $\begin{array}{c}0.270^{* * *} \\
(0.034)\end{array}$ & -- \\
\hline GJR $\gamma$ & -- & $\begin{array}{c}-0.286 * * * \\
(0.025)\end{array}$ & -- \\
\hline EGARCH $\alpha$ & -- & -- & $\begin{array}{c}0.288 * * * \\
(0.016)\end{array}$ \\
\hline EGARCH $\gamma$ & -- & -- & $\begin{array}{c}0.169 * * * \\
(0.012)\end{array}$ \\
\hline EGARCH $\beta$ & -- & -- & $\begin{array}{c}0.614 * * * \\
(0.029)\end{array}$ \\
\hline \multicolumn{4}{|l|}{ Diagnostics } \\
\hline AIC & 15.732 & 15.718 & 15.723 \\
\hline BIC & 15.738 & 15.725 & 15.730 \\
\hline $\begin{array}{l}\text { Jarque-Bera } \\
\text { [p-value] }\end{array}$ & $\begin{array}{c}692.40 \\
{[0.000]}\end{array}$ & $\begin{array}{l}605.16 \\
{[0.000]}\end{array}$ & $\begin{array}{l}587.40 \\
{[0.000]}\end{array}$ \\
\hline $\begin{array}{l}\text { Causality } t \text { test } \\
\text { [p-value] }\end{array}$ & $\begin{array}{l}-3.022 \\
{[0.003]}\end{array}$ & $\begin{array}{l}-3.048 \\
{[0.002]}\end{array}$ & $\begin{array}{l}-2.614 \\
{[0.009]}\end{array}$ \\
\hline
\end{tabular}

Notes: The dependent variable is Japanese daily tourist arrivals to Taiwan. Numbers in parentheses are standard errors. The log-moment condition is necessarily satisfied as the second moment condition is satisfied.

$\mathrm{AIC}$ and BIC denote the Akaike Information Criterion and Schwarz Bayesian Information Criterion, respectively.

*** denotes the estimated coefficients are statistically significant at the $1 \%$ level .

The volatility of the exchange rate is taken to be the squared deviation from the mean exchange rate. 
Table 4a: HAR(1) Conditional Mean and Conditional Volatility Models for US Daily Tourist Arrivals to Taiwan, with HAR(1) Exchange Rates

\begin{tabular}{|c|c|c|c|}
\hline Parameters & GARCH & GJR & EGARCH \\
\hline$\phi_{1}$ & $\begin{array}{c}816.94 * * * \\
(26.75)\end{array}$ & $\begin{array}{c}808.35 * * * \\
(27.15)\end{array}$ & $\begin{array}{c}836.05 * * * \\
(26.06)\end{array}$ \\
\hline$\phi_{21}$ & $\begin{array}{c}0.592 * * * \\
(0.010)\end{array}$ & $\begin{array}{c}0.593 * * * \\
(0.010)\end{array}$ & $\begin{array}{c}0.588 * * * \\
(0.010)\end{array}$ \\
\hline$\phi_{22}$ & $\begin{array}{c}-13339 * * * \\
(632.3)\end{array}$ & $\begin{array}{c}-13099 * * * \\
(639.4)\end{array}$ & $\begin{array}{c}-13746 * * * \\
(613.87)\end{array}$ \\
\hline$\omega$ & $\begin{array}{c}603.06^{* * * *} \\
(78.25)\end{array}$ & $\begin{array}{c}697.78^{* * * *} \\
(88.49)\end{array}$ & $\begin{array}{l}0.098 * * \\
(0.026)\end{array}$ \\
\hline GARCH/GJR $\alpha$ & $\begin{array}{c}0.053 * * * \\
(0.003)\end{array}$ & $\begin{array}{c}0.060^{* * * *} \\
(0.004)\end{array}$ & - \\
\hline GARCH/GJR $\beta$ & $\begin{array}{c}0.931 * * * \\
(0.004)\end{array}$ & $\begin{array}{c}0.924 * * * \\
(0.005)\end{array}$ & -- \\
\hline GJR $\gamma$ & -- & $\begin{array}{l}-0.010^{*} \\
(0.005)\end{array}$ & -- \\
\hline EGARCH $\alpha$ & -- & -- & $\begin{array}{c}0.117 * * * \\
(0.006)\end{array}$ \\
\hline EGARCH $\gamma$ & -- & -- & $\begin{array}{c}0.011 * * * \\
(0.003)\end{array}$ \\
\hline EGARCH $\beta$ & -- & -- & $\begin{array}{c}0.982 * * * \\
(0.003)\end{array}$ \\
\hline \multicolumn{4}{|l|}{ Diagnostics } \\
\hline AIC & 13.156 & 13.155 & 13.156 \\
\hline $\mathrm{BIC}$ & 13.161 & 13.162 & 13.163 \\
\hline $\begin{array}{l}\text { Jarque-Bera } \\
\text { [p-value] }\end{array}$ & $\begin{array}{l}1564.11 \\
{[0.000]}\end{array}$ & $\begin{array}{c}1487.71 . \\
{[0.000]}\end{array}$ & $\begin{array}{l}1788.54 \\
{[0.000]}\end{array}$ \\
\hline $\begin{array}{l}\text { Causality } t \text { test } \\
\text { [p-value] }\end{array}$ & $\begin{array}{c}-21.09 \\
{[0.000]}\end{array}$ & $\begin{array}{l}-20.49 \\
{[0.000]}\end{array}$ & $\begin{array}{l}-22.39 \\
{[0.000]}\end{array}$ \\
\hline
\end{tabular}

Notes: The dependent variable is US daily tourist arrivals to Taiwan. Numbers in parentheses are standard errors. The log-moment condition is necessarily satisfied as the second moment condition is satisfied.

AIC and BIC denote the Akaike Information Criterion and Schwarz Bayesian Information Criterion, respectively. $* * *$ and $*$ denote the estimated coefficients are statistically significant at the $1 \%$ and $10 \%$ levels, respectively. 
Table 4b: HAR(1) Conditional Mean and Conditional Volatility Models for US Daily Tourist Arrivals to Taiwan, with HAR(1) Exchange Rate Volatility

\begin{tabular}{lccc}
\hline Parameters & GARCH & GJR & EGARCH \\
\hline$\phi_{1}$ & $289.32^{* * *}$ & $323.8^{* * *}$ & $277.13^{* * *}$ \\
$\phi_{21}$ & $(9.782)$ & $(9.704)$ & $(9.441)$ \\
$\phi_{22}$ & $0.726^{* * *}$ & $0.677^{* * *}$ & $0.739^{* * *}$ \\
\hline$\omega$ & $(0.008)$ & $(0.009)$ & $(0.008)$ \\
& $-2610245^{* * *}$ & $-2528663^{* * *}$ & $-2532743^{* * *}$ \\
GARCH/GJR $\alpha$ & $(231103)$ & $(226931)$ & $(220450)$ \\
GARCH/GJR $\beta$ & $29093^{* * *}$ & $1063.1 * * *$ & $10.94^{* * *}$ \\
& $(981.2)$ & $(125.47)$ & $(0.351)$ \\
GJR $\gamma$ & $0.209^{* * *}$ & $0.070^{* * *}$ & -- \\
EGARCH $\alpha$ & $(0.011)$ & $(0.005)$ & -- \\
EGARCH $\gamma$ & $-0.092^{* * *}$ & $0.911^{* * *}$ & -- \\
EGARCH $\beta$ & $(0.027)$ & $(0.006)$ & $0.410^{* * *}$ \\
\hline Diagnostics & -- & $-0.030^{* * *}$ & $(0.016)$ \\
AIC & $--0.006)$ & -0.008 \\
BIC & $--009)$ \\
Jarque-Bera & -- & -- & $-0.086^{* *}$ \\
[p-value] & & -- & $(0.034)$ \\
Causality $t$ test & & & \\
[p-value] & & -- & 13.206 \\
\hline
\end{tabular}

Notes: The dependent variable is US daily tourist arrivals to Taiwan. Numbers in parentheses are standard errors. The log-moment condition is necessarily satisfied as the second moment condition is satisfied.

AIC and BIC denote the Akaike Information Criterion and Schwarz Bayesian Information Criterion, respectively. $* * *$ and $* *$ denote the estimated coefficients are statistically significant at the $1 \%$ and $5 \%$ levels, respectively.

The volatility of the exchange rate is taken to be the squared deviation from the mean exchange rate. 
Table 5a: HAR(1) Conditional Mean and Conditional Volatility Models for World Weekly Tourist Arrivals to Taiwan, with HAR(1) Exchange Rates

\begin{tabular}{|c|c|c|c|}
\hline Parameters & GARCH & GJR & EGARCH \\
\hline$\phi_{1}$ & $\begin{array}{c}5517.5^{* * * *} \\
(1371.4)\end{array}$ & $\begin{array}{c}6006.3 * * * \\
(1612)\end{array}$ & $\begin{array}{c}5094 * * * \\
(1428)\end{array}$ \\
\hline$\phi_{21}$ & $\begin{array}{c}0.900 * * * \\
(0.013)\end{array}$ & $\begin{array}{c}0.894 * * * \\
(0.015)\end{array}$ & $\begin{array}{c}0.900 * * * \\
(0.013)\end{array}$ \\
\hline$\phi_{22}$ & $\begin{array}{l}-14.265 \\
(12.34)\end{array}$ & $\begin{array}{l}-21.23 \\
(14.09)\end{array}$ & $\begin{array}{l}-13.83 \\
(12.74)\end{array}$ \\
\hline$\omega$ & $\begin{array}{c}14164270^{* * * *} \\
(1435483)\end{array}$ & $\begin{array}{c}17991048 * * * \\
(1274676)\end{array}$ & $\begin{array}{c}8.240 * * * \\
(1.017)\end{array}$ \\
\hline GARCH/GJR $\alpha$ & $\begin{array}{c}0.411 * * * \\
(0.048)\end{array}$ & $\begin{array}{c}0.053 \\
(0.038)\end{array}$ & -- \\
\hline GARCH/GJR $\beta$ & $\begin{array}{c}0.130^{* *} \\
(0.053)\end{array}$ & $\begin{array}{c}0.094 * * * \\
(0.036)\end{array}$ & -- \\
\hline GJR $\gamma$ & -- & $\begin{array}{c}0.637 * * * \\
(0.110)\end{array}$ & -- \\
\hline EGARCH $\alpha$ & -- & -- & $\begin{array}{c}0.539 * * * \\
(0.059)\end{array}$ \\
\hline EGARCH $\gamma$ & -- & -- & $\begin{array}{c}-0.228 * * * \\
(0.042)\end{array}$ \\
\hline EGARCH $\beta$ & -- & -- & $\begin{array}{c}0.492 * * * \\
(0.060) \\
\end{array}$ \\
\hline \multicolumn{4}{|l|}{ Diagnostics } \\
\hline AIC & 19.882 & 19.865 & 19.861 \\
\hline BIC & 19.912 & 19.899 & 19.895 \\
\hline $\begin{array}{l}\text { Jarque-Bera } \\
\text { [p-value] }\end{array}$ & $\begin{array}{l}152.38 \\
{[0.000]}\end{array}$ & $\begin{array}{l}141.67 \\
{[0.000]}\end{array}$ & $\begin{array}{l}132.82 \\
{[0.000]}\end{array}$ \\
\hline $\begin{array}{l}\text { Causality } t \text { test } \\
\text { [p-value] }\end{array}$ & $\begin{array}{c}-1.165 \\
{[0.244]} \\
\end{array}$ & $\begin{array}{c}-1.507 \\
{[0.132]} \\
\end{array}$ & $\begin{array}{c}-1.086 \\
{[0.278]} \\
\end{array}$ \\
\hline
\end{tabular}

Notes: The dependent variable is world weekly tourist arrivals to Taiwan. Numbers in parentheses are standard errors. The log-moment condition is necessarily satisfied as the second moment condition is satisfied.

AIC and BIC denote the Akaike Information Criterion and Schwarz Bayesian Information Criterion, respectively. $* * *$ and $*$ denote the estimated coefficients are statistically significant at the $1 \%$ and $5 \%$ levels, respectively. 
Table 5b: HAR(1) Conditional Mean and Conditional Volatility Models for World Weekly Tourist Arrivals to Taiwan, with HAR(1) Exchange Rate Volatility

\begin{tabular}{|c|c|c|c|}
\hline Parameters & GARCH & GJR & EGARCH \\
\hline$\phi_{1}$ & $\begin{array}{c}4239.1 * * * \\
(542.3)\end{array}$ & $\begin{array}{c}3820.4 * * * \\
(592.7)\end{array}$ & $\begin{array}{c}3876.3 * * * \\
(578.20)\end{array}$ \\
\hline$\phi_{21}$ & $\begin{array}{c}0.894 * * * \\
(0.013)\end{array}$ & $\begin{array}{c}0.896^{* * * *} \\
(0.014)\end{array}$ & $\begin{array}{c}0.894 * * * \\
(0.014)\end{array}$ \\
\hline$\phi_{22}$ & $\begin{array}{l}1.655^{*} \\
(0.854)\end{array}$ & $\begin{array}{c}1.496 \\
(0.943)\end{array}$ & $\begin{array}{l}1.400 \\
(0.919)\end{array}$ \\
\hline$\omega$ & $\begin{array}{c}14140895 * * * \\
(1456447)\end{array}$ & $\begin{array}{c}13149527 * * * \\
(1448722)\end{array}$ & $\begin{array}{c}8.257 * * * \\
(1.025)\end{array}$ \\
\hline GARCH/GJR $\alpha$ & $\begin{array}{c}0.401 * * * \\
(0.047)\end{array}$ & $\begin{array}{c}0.096^{* *} \\
(0.043)\end{array}$ & - \\
\hline GARCH/GJR $\beta$ & $\begin{array}{c}0.134 * * \\
(0.054)\end{array}$ & $\begin{array}{c}0.210 * * * \\
(0.060)\end{array}$ & -- \\
\hline GJR $\gamma$ & -- & $\begin{array}{c}0.568 * * * \\
(0.108)\end{array}$ & -- \\
\hline EGARCH $\alpha$ & -- & -- & $\begin{array}{c}0.549 * * * \\
(0.059)\end{array}$ \\
\hline EGARCH $\gamma$ & -- & -- & $\begin{array}{c}-0.221 * * * \\
(0.0430)\end{array}$ \\
\hline EGARCH $\beta$ & -- & -- & $\begin{array}{c}0.491 * * * \\
(0.061) \\
\end{array}$ \\
\hline \multicolumn{4}{|l|}{ Diagnostics } \\
\hline AIC & 19.879 & 19.855 & 19.859 \\
\hline $\mathrm{BIC}$ & 19.909 & 19.890 & 19.894 \\
\hline $\begin{array}{l}\text { Jarque-Bera } \\
\text { [p-value] }\end{array}$ & $\begin{array}{l}148.63 \\
{[0.000]}\end{array}$ & $\begin{array}{l}128.79 \\
{[0.000]}\end{array}$ & $\begin{array}{l}125.40 \\
{[0.000]}\end{array}$ \\
\hline $\begin{array}{l}\text { Causality } t \text { test } \\
\text { [p-value] }\end{array}$ & $\begin{array}{c}1.938 \\
{[0.053]}\end{array}$ & $\begin{array}{c}1.587 \\
{[0.113]}\end{array}$ & $\begin{array}{c}1.524 \\
{[0.128]}\end{array}$ \\
\hline
\end{tabular}

Notes: The dependent variable is world weekly tourist arrivals to Taiwan. Numbers in parentheses are standard errors. The log-moment condition is necessarily satisfied as the second moment condition is satisfied.

$\mathrm{AIC}$ and BIC denote the Akaike Information Criterion and Schwarz Bayesian Information Criterion, respectively.

$* * *, * *$ and $*$ denote the estimated coefficients are statistically significant at the $1 \%, 5 \%$ and $10 \%$ levels, respectively.

The volatility of the exchange rate is taken to be the squared deviation from the mean exchange rate. 
Table 6a: HAR(1) Conditional Mean and Conditional Volatility Models for Japanese Weekly Tourist Arrivals to Taiwan, with HAR(1) Exchange Rates

\begin{tabular}{|c|c|c|c|}
\hline Parameters & GARCH & GJR & EGARCH \\
\hline$\phi_{1}$ & $\begin{array}{c}8461.4 * * * \\
(861.4)\end{array}$ & $\begin{array}{c}\text { 8416*** } \\
(861.1)\end{array}$ & $\begin{array}{c}8274.8 * * * \\
(848.7)\end{array}$ \\
\hline$\phi_{21}$ & $\begin{array}{c}0.633 * * * \\
(0.027)\end{array}$ & $\begin{array}{c}0.631 * * * \\
(0.027)\end{array}$ & $\begin{array}{c}0.631 * * * \\
(0.026)\end{array}$ \\
\hline$\phi_{22}$ & $\begin{array}{c}-536.81 * * * \\
(160.7)\end{array}$ & $\begin{array}{c}-513.8 * * * \\
(166.6)\end{array}$ & $\begin{array}{c}-485.5^{*} * * \\
(168.9)\end{array}$ \\
\hline$\omega$ & $\begin{array}{c}1536692 * * * \\
(538185)\end{array}$ & $\begin{array}{c}1337882 * * * \\
(472402)\end{array}$ & $\begin{array}{l}1.694 * * \\
(0.625)\end{array}$ \\
\hline GARCH/GJR $\alpha$ & $\begin{array}{c}0.104 * * * \\
(0.026)\end{array}$ & $\begin{array}{c}0.116^{* * *} \\
(0.038)\end{array}$ & -- \\
\hline GARCH/GJR $\beta$ & $\begin{array}{c}0.757 * * * \\
(0.066)\end{array}$ & $\begin{array}{c}0.782 * * * \\
(0.059)\end{array}$ & -- \\
\hline GJR $\gamma$ & -- & $\begin{array}{l}-0.039 \\
(0.043)\end{array}$ & -- \\
\hline EGARCH $\alpha$ & -- & - & $\begin{array}{c}0.185 * * * \\
(0.041)\end{array}$ \\
\hline EGARCH $\gamma$ & -- & -- & $\begin{array}{l}0.045^{*} \\
(0.026)\end{array}$ \\
\hline EGARCH $\beta$ & -- & -- & $\begin{array}{c}0.886 * * * \\
(0.040) \\
\end{array}$ \\
\hline \multicolumn{4}{|l|}{ Diagnostics } \\
\hline AIC & 19.040 & 19.041 & 19.045 \\
\hline $\mathrm{BIC}$ & 19.069 & 19.075 & 19.080 \\
\hline $\begin{array}{l}\text { Jarque-Bera } \\
\text { [p-value] }\end{array}$ & $\begin{array}{l}18.589 \\
{[0.000]}\end{array}$ & $\begin{array}{l}19.244 \\
{[0.000]}\end{array}$ & $\begin{array}{l}17.293 \\
{[0.000]}\end{array}$ \\
\hline $\begin{array}{l}\text { Causality } t \text { test } \\
\text { [p-value] }\end{array}$ & $\begin{array}{c}-3.339 \\
{[0.000]}\end{array}$ & $\begin{array}{l}-3.084 \\
{[0.002]}\end{array}$ & $\begin{array}{l}-2.874 \\
{[0.004]}\end{array}$ \\
\hline
\end{tabular}

Notes: The dependent variable is Japanese weekly tourist arrivals to Taiwan. Numbers in parentheses are standard errors. The log-moment condition is necessarily satisfied as the second moment condition is satisfied.

AIC and BIC denote the Akaike Information Criterion and Schwarz Bayesian Information Criterion, respectively. $* * *$ and $*$ denote the estimated coefficients are statistically significant at the $1 \%$ and $10 \%$ levels, respectively. 
Table 6b: HAR(1) Conditional Mean and Conditional Volatility Models for Japanese Weekly Tourist Arrivals to Taiwan, with HAR(1) Exchange Rate Volatility

\begin{tabular}{|c|c|c|c|}
\hline Parameters & GARCH & GJR & EGARCH \\
\hline$\phi_{1}$ & $\begin{array}{c}6123.9 * * * \\
(489.7)\end{array}$ & $\begin{array}{c}6231.3 * * * \\
(468.8)\end{array}$ & $\begin{array}{c}6274.5 * * * \\
(451.7)\end{array}$ \\
\hline & $0.653 * * *$ & $0.647 * * *$ & $0.642 * * *$ \\
\hline$\phi_{21}$ & $(0.027)$ & $(0.027)$ & $(0.026)$ \\
\hline$\phi_{22}$ & $\begin{array}{l}-262.9^{*} \\
(141.5)\end{array}$ & $\begin{array}{l}-258.5^{*} \\
(151.5)\end{array}$ & $\begin{array}{l}-235.2 \\
(152.7)\end{array}$ \\
\hline$\omega$ & $\begin{array}{c}1562706^{* * *} \\
(547460)\end{array}$ & $\begin{array}{c}1281911^{* * * *} \\
(442608)\end{array}$ & $\begin{array}{c}1.669 * * * \\
(0.594)\end{array}$ \\
\hline GARCH/GJR $\alpha$ & $\begin{array}{c}0.104 * * * \\
(0.025)\end{array}$ & $\begin{array}{c}0.120^{* * * *} \\
(0.038)\end{array}$ & -- \\
\hline GARCH/GJR $\beta$ & $\begin{array}{c}0.755^{* * * *} \\
(0.066)\end{array}$ & $\begin{array}{c}0.790 * * * \\
(0.055)\end{array}$ & -- \\
\hline GJR $\gamma$ & -- & $\begin{array}{l}-0.054 \\
(0.043)\end{array}$ & -- \\
\hline EGARCH $\alpha$ & -- & -- & $\begin{array}{c}0.177 * * * \\
(0.039)\end{array}$ \\
\hline EGARCH $\gamma$ & -- & -- & $\begin{array}{c}0.052 * * \\
(0.026)\end{array}$ \\
\hline EGARCH $\beta$ & -- & -- & $\begin{array}{c}0.888 * * * \\
(0.0378) \\
\end{array}$ \\
\hline \multicolumn{4}{|l|}{ Diagnostics } \\
\hline AIC & 19.047 & 19.047 & 19.051 \\
\hline $\mathrm{BIC}$ & 19.076 & 19.081 & 19.086 \\
\hline $\begin{array}{l}\text { Jarque-Bera } \\
\text { [p-value] }\end{array}$ & $\begin{array}{l}16.268 \\
{[0.000]}\end{array}$ & $\begin{array}{l}17.295 \\
{[0.000]}\end{array}$ & $\begin{array}{l}15.445 \\
{[0.000]}\end{array}$ \\
\hline $\begin{array}{l}\text { Causality } t \text { test } \\
\text { [p-value] }\end{array}$ & $\begin{array}{l}-1.858 \\
{[0.064]}\end{array}$ & $\begin{array}{l}-1.707 \\
{[0.088]}\end{array}$ & $\begin{array}{l}-1.540 \\
{[0.124]}\end{array}$ \\
\hline
\end{tabular}

Notes: The dependent variable is Japanese weekly tourist arrivals to Taiwan. Numbers in parentheses are standard errors. The log-moment condition is necessarily satisfied as the second moment condition is satisfied.

AIC and BIC denote the Akaike Information Criterion and Schwarz Bayesian Information Criterion, respectively.

$* * *, * *$ and $*$ denote the estimated coefficients are statistically significant at the $1 \%, 5 \%$ and $10 \%$ levels, respectively.

The volatility of the exchange rate is taken to be the squared deviation from the mean exchange rate. 
Table 7a: HAR(1) Conditional Mean and Conditional Volatility Models for US Weekly Tourist Arrivals to Taiwan, with HAR(1) Exchange Rates

\begin{tabular}{|c|c|c|c|}
\hline Parameters & GARCH & GJR & EGARCH \\
\hline$\phi_{1}$ & $\begin{array}{c}3434.8 * * * \\
(395.06)\end{array}$ & $\begin{array}{c}2663.4 * * * \\
(324.62)\end{array}$ & $\begin{array}{c}2639.5 * * * \\
(289.74)\end{array}$ \\
\hline$\phi_{21}$ & $\begin{array}{c}0.751 * * * \\
(0.022)\end{array}$ & $\begin{array}{c}0.799 * * * \\
(0.020)\end{array}$ & $\begin{array}{c}0.795^{* * *} \\
(0.019)\end{array}$ \\
\hline$\phi_{22}$ & $\begin{array}{c}-56075 * * * \\
(8521.3)\end{array}$ & $\begin{array}{c}-40623 * * * \\
(7081.7)\end{array}$ & $\begin{array}{c}-39491 * * * \\
(6248.4)\end{array}$ \\
\hline$\omega$ & $\begin{array}{c}269004 * * * \\
(38322)\end{array}$ & $\begin{array}{c}229228 * * * \\
(35754)\end{array}$ & $\begin{array}{c}3.614 * * * \\
(0.687)\end{array}$ \\
\hline GARCH/GJR $\alpha$ & $\begin{array}{c}0.352 * * * \\
(0.045)\end{array}$ & $\begin{array}{c}0.650 * * * \\
(0.101)\end{array}$ & -- \\
\hline GARCH/GJR $\beta$ & $\begin{array}{c}0.298 * * * \\
(0.647)\end{array}$ & $\begin{array}{c}0.366^{* * * *} \\
(0.063)\end{array}$ & -- \\
\hline GJR $\gamma$ & -- & $\begin{array}{c}-0.588 * * * \\
(0.104)\end{array}$ & -- \\
\hline EGARCH $\alpha$ & -- & -- & $\begin{array}{c}0.436 * * * \\
(0.055)\end{array}$ \\
\hline EGARCH $\gamma$ & -- & -- & $\begin{array}{c}0.257 * * * \\
(0.039)\end{array}$ \\
\hline EGARCH $\beta$ & -- & -- & $\begin{array}{c}0.703 * * * \\
(0.052) \\
\end{array}$ \\
\hline \multicolumn{4}{|l|}{ Diagnostics } \\
\hline AIC & 16.206 & 16.152 & 16.156 \\
\hline BIC & 16.235 & 16.187 & 16.190 \\
\hline $\begin{array}{l}\text { Jarque-Bera } \\
\text { [p-value] }\end{array}$ & $\begin{array}{l}96.256 \\
{[0.000]}\end{array}$ & $\begin{array}{l}58.224 \\
{[0.000]}\end{array}$ & $\begin{array}{l}46.853 \\
{[0.000]}\end{array}$ \\
\hline $\begin{array}{l}\text { Causality } t \text { test } \\
\text { [p-value] }\end{array}$ & $\begin{array}{c}-6.581 \\
{[0.000]}\end{array}$ & $\begin{array}{c}-5.736 \\
{[0.000]}\end{array}$ & $\begin{array}{c}-6.320 \\
{[0.000]}\end{array}$ \\
\hline
\end{tabular}

Notes: The dependent variable is US weekly tourist arrivals to Taiwan. Numbers in parentheses are standard errors. The log-moment condition is necessarily satisfied as the second moment condition is satisfied.

AIC and BIC denote the Akaike Information Criterion and Schwarz Bayesian Information Criterion, respectively. *** denotes the estimated coefficients are statistically significant at the $1 \%$ level. 
Table 7b: HAR(1) Conditional Mean and Conditional Volatility Models for US Weekly Tourist Arrivals to Taiwan, with HAR(1) Exchange Rate Volatility

\begin{tabular}{|c|c|c|c|}
\hline Parameters & GARCH & GJR & EGARCH \\
\hline$\phi_{1}$ & $\begin{array}{c}1246.7 * * * \\
(147.9)\end{array}$ & $\begin{array}{c}1140.0 * * * \\
(126.3)\end{array}$ & $\begin{array}{c}1106.2 * * * \\
(115.0)\end{array}$ \\
\hline$\phi_{21}$ & $\begin{array}{c}0.818 * * * \\
(0.019)\end{array}$ & $\begin{array}{c}0.844 * * * \\
(0.018)\end{array}$ & $\begin{array}{c}0.845^{* * *} \\
(0.017)\end{array}$ \\
\hline$\phi_{22}$ & $\begin{array}{c}-9975660 * * * \\
(2851850)\end{array}$ & $\begin{array}{c}-8772370 * * * \\
(2405406)\end{array}$ & $\begin{array}{c}-7346477 * * * \\
(2136266)\end{array}$ \\
\hline$\omega$ & $\begin{array}{c}260330 * * * \\
(43405)\end{array}$ & $\begin{array}{c}215965 * * * \\
(35607)\end{array}$ & $\begin{array}{c}3.384 * * * \\
(0.639)\end{array}$ \\
\hline GARCH/GJR $\alpha$ & $\begin{array}{c}0.321 * * * \\
(0.044)\end{array}$ & $\begin{array}{c}0.618^{* * *} \\
(0.099)\end{array}$ & -- \\
\hline GARCH/GJR $\beta$ & $\begin{array}{c}0.343 * * * \\
(0.073)\end{array}$ & $\begin{array}{c}0.427 * * * \\
(0.064)\end{array}$ & -- \\
\hline GJR $\gamma$ & -- & $\begin{array}{c}-0.608 * * * \\
(0.100)\end{array}$ & -- \\
\hline EGARCH $\alpha$ & -- & -- & $\begin{array}{c}0.323 * * * \\
(0.050)\end{array}$ \\
\hline EGARCH $\gamma$ & -- & -- & $\begin{array}{c}0.287 * * * \\
(0.038)\end{array}$ \\
\hline EGARCH $\beta$ & -- & -- & $\begin{array}{c}0.728 * * * \\
(0.049) \\
\end{array}$ \\
\hline \multicolumn{4}{|l|}{ Diagnostics } \\
\hline AIC & 16.236 & 16.165 & 16.171 \\
\hline $\mathrm{BIC}$ & 16.266 & 16.200 & 16.206 \\
\hline $\begin{array}{l}\text { Jarque-Bera } \\
\text { [p-value] }\end{array}$ & $\begin{array}{l}100.17 \\
{[0.000]}\end{array}$ & $\begin{array}{c}42.842 \\
{[0.000]}\end{array}$ & $\begin{array}{l}35.103 \\
{[0.000]}\end{array}$ \\
\hline $\begin{array}{l}\text { Causality } t \text { test } \\
\text { [p-value] }\end{array}$ & $\begin{array}{l}-3.498 \\
{[0.001]}\end{array}$ & $\begin{array}{c}-3.649 \\
{[0.000]}\end{array}$ & $\begin{array}{l}-3.439 \\
{[0.001]}\end{array}$ \\
\hline
\end{tabular}

Notes: The dependent variable is US weekly tourist arrivals to Taiwan. Numbers in parentheses are standard errors. The log-moment condition is necessarily satisfied as the second moment condition is satisfied. AIC and BIC denote the Akaike Information Criterion and Schwarz Bayesian Information Criterion, respectively. $* * *$ denotes the estimated coefficients are statistically significant at the $1 \%$ level.

The volatility of the exchange rate is taken to be the squared deviation from the mean exchange rate. 
Figure 1. Daily Tourist Arrivals to Taiwan and Volatility
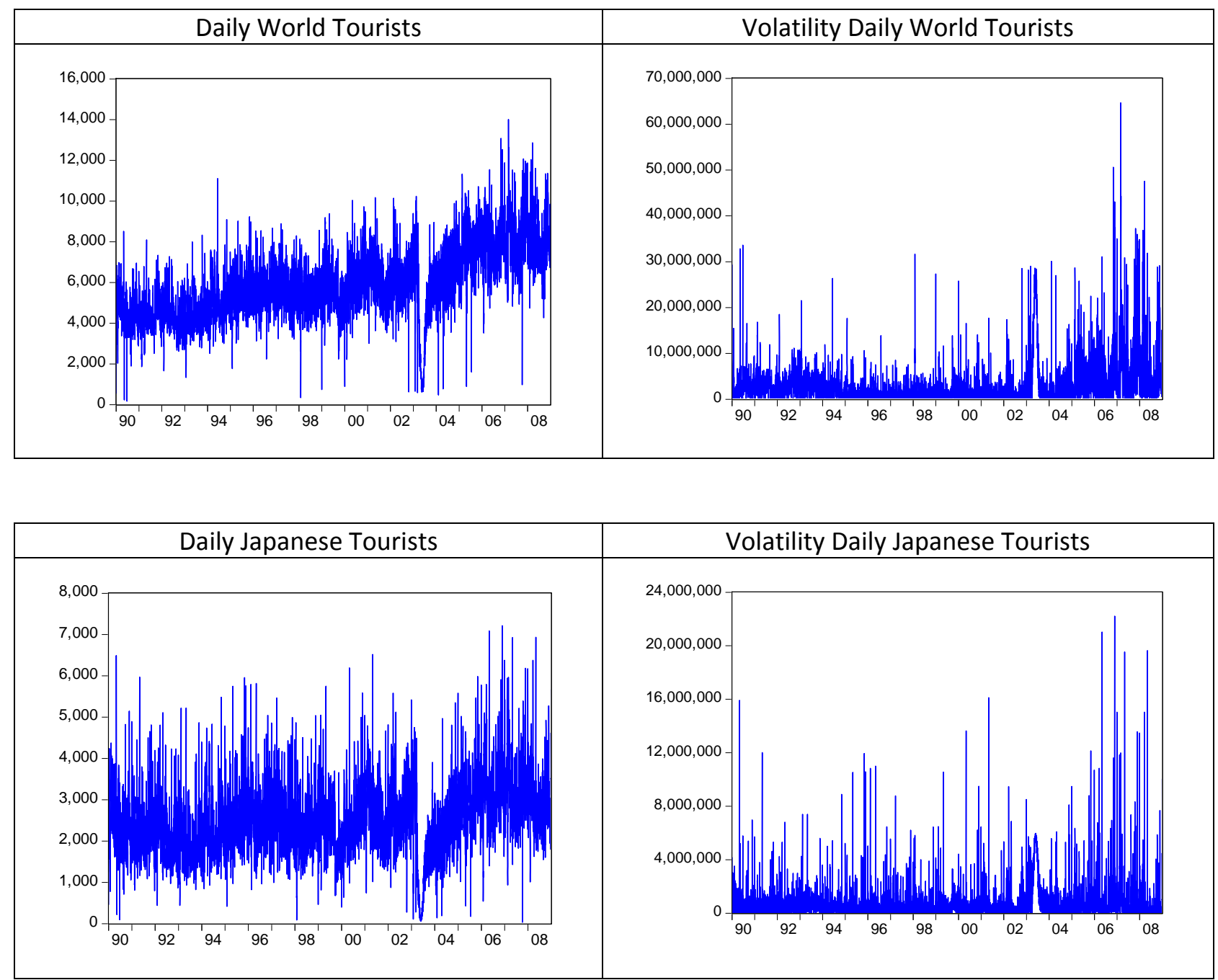

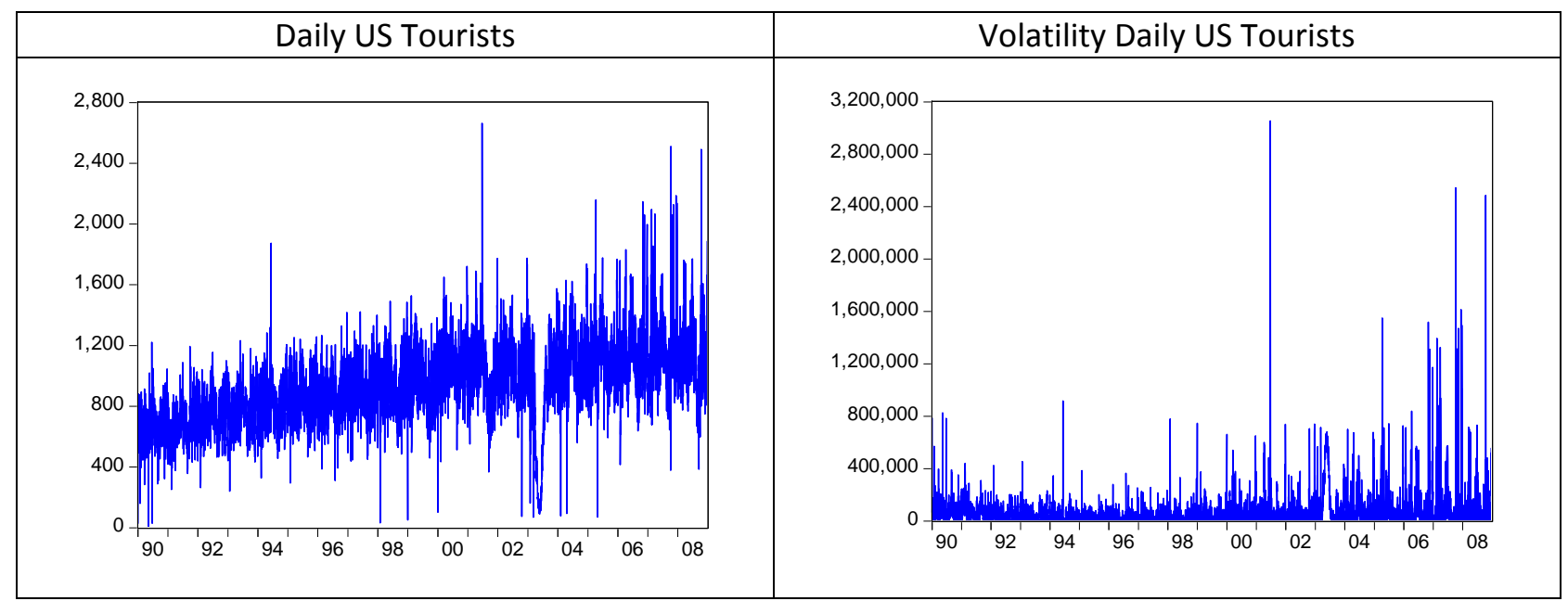


Figure 2. Weekly Tourist Arrivals to Taiwan and Volatility
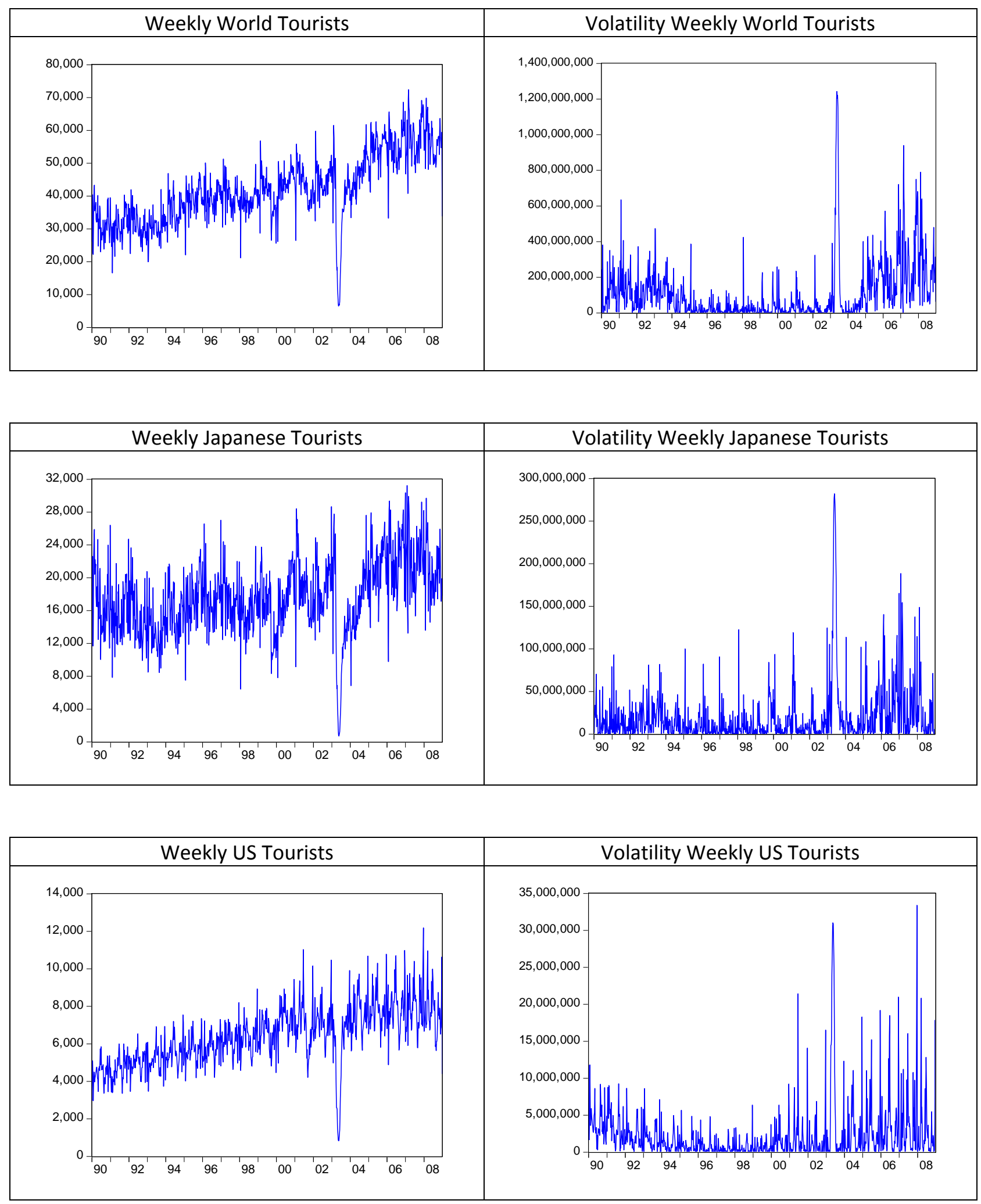
Figure 3. Daily Exchange Rates and Volatility
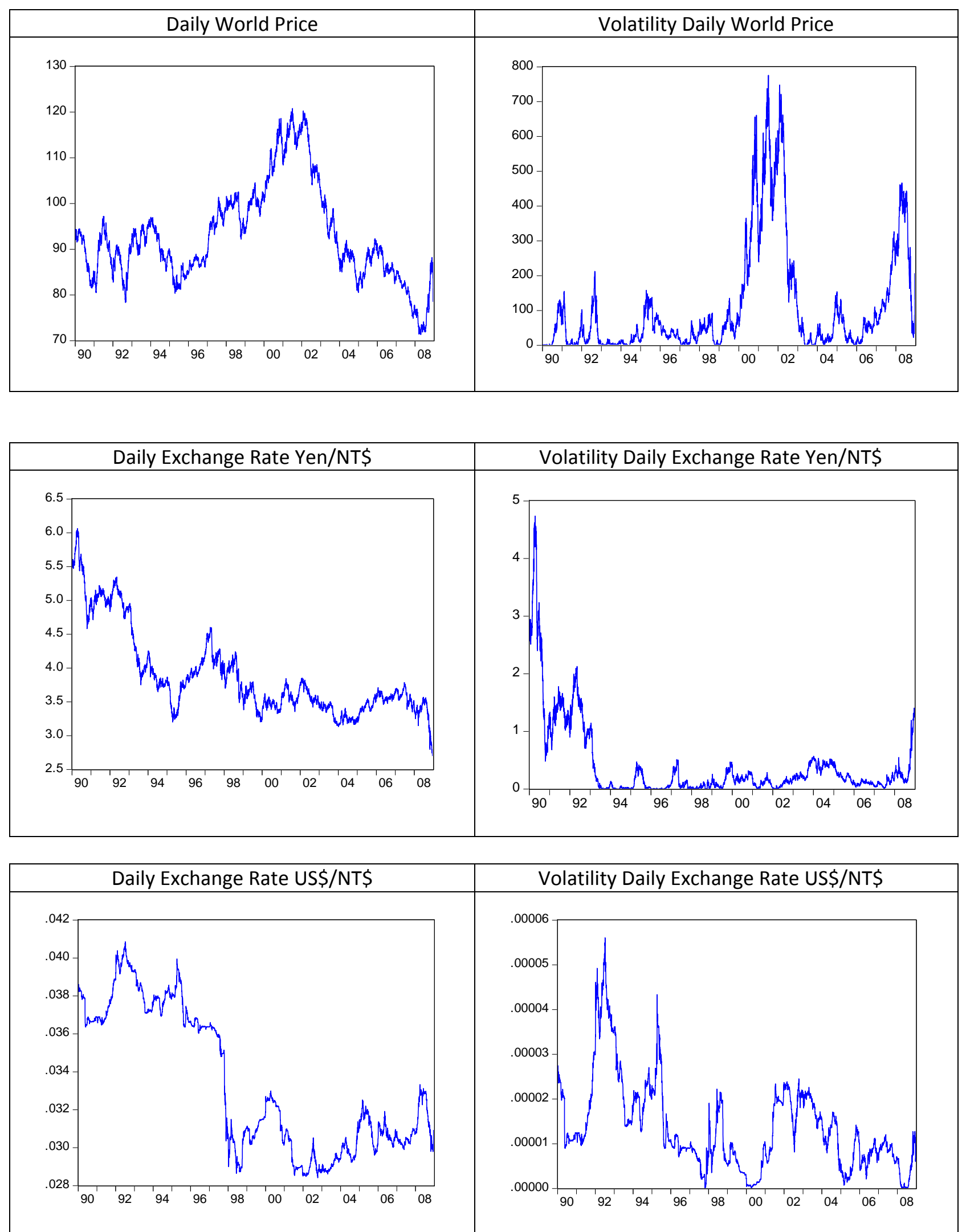
Figure 4. Weekly Exchange Rates and Volatility
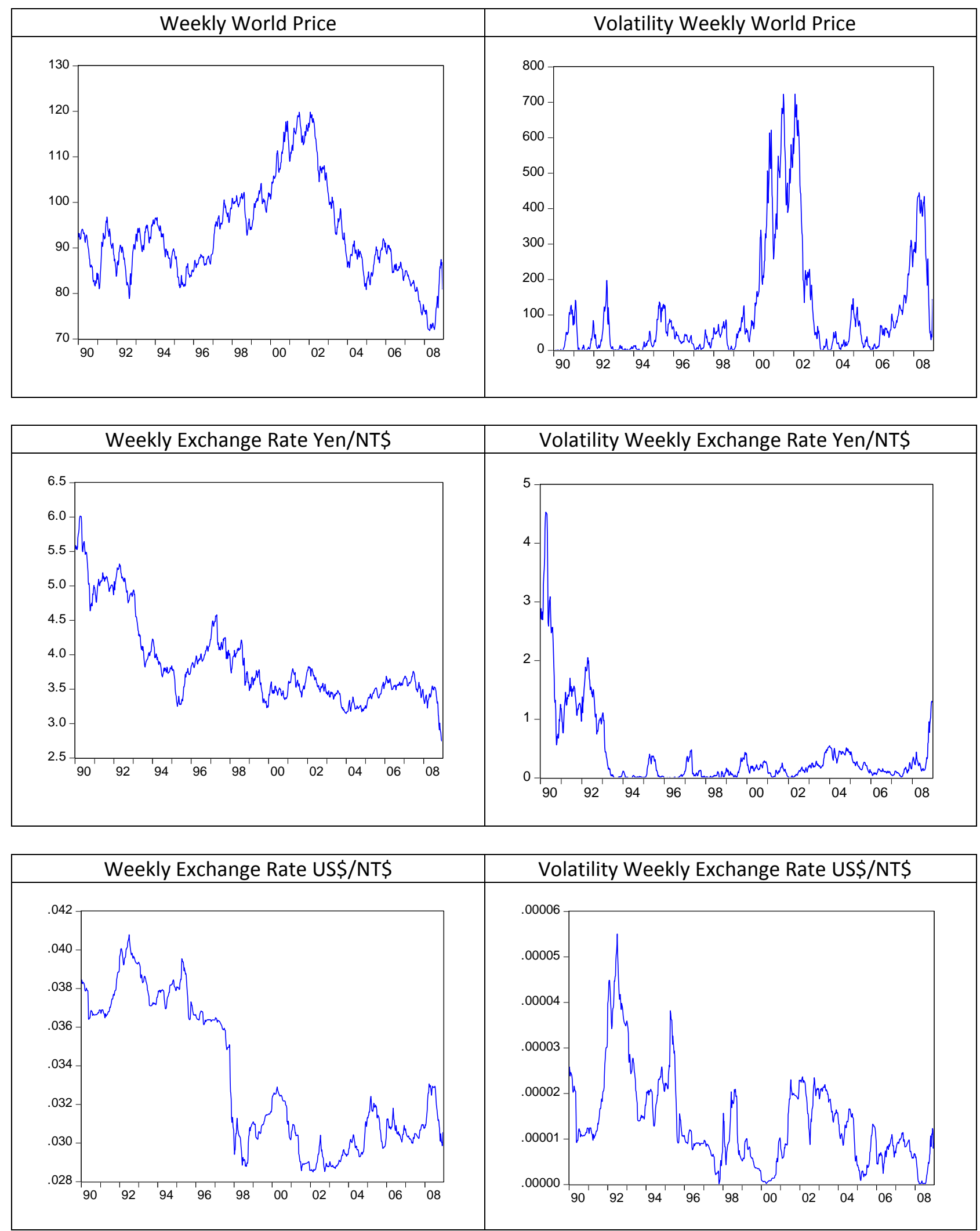